\title{
Aerodynamic Optimization Design of a Supersonic Compressor Rotor with High Pressure Ratio
}

\author{
Cui Cui $\mathbb{D}^{1}{ }^{1}$ Zhenggui Zhou $\left(\mathbb{D},{ }^{1,2}\right.$ and Endor Liu $\mathbb{D}^{1}$ \\ ${ }^{1}$ Jiangsu Province Key Laboratory of Aerospace Power Systems, College of Energy and Power Engineering, Nanjing University of \\ Aeronautics and Astronautics, Nanjing 210000, China \\ ${ }^{2}$ College of Energy and Power Engineering, Nanjing University of Aeronautics and Astronautics, No. 29, Yudao Street, Nanjing, \\ Jiangsu, China
}

Correspondence should be addressed to Zhenggui Zhou; zzgon@nuaa.edu.cn

Received 8 November 2020; Revised 28 January 2021; Accepted 20 February 2021; Published 10 March 2021

Academic Editor: Jiaqiang E

Copyright (C) 2021 Cui Cui et al. This is an open access article distributed under the Creative Commons Attribution License, which permits unrestricted use, distribution, and reproduction in any medium, provided the original work is properly cited.

\begin{abstract}
Supersonic compressors have a high wheel speed and operational capability, which facilitate a high stage pressure ratio. However, the strong shock waves in the passage of a supersonic rotor and the interference between shock waves and boundary layers can lead to large flow loss and low efficiency. Moreover, the existing design of a high-load supersonic compressor has the problem of small stall margin. In this study, an automatic optimization method including 2D profile optimization and 3D blade optimization is proposed to achieve a high efficiency at the design point of a supersonic compressor rotor under the premise of reaching the desired mass flow rate and total pressure ratio. According to the analysis of flow near the stall point of the supersonic compressor rotor, the mechanism responsible for rotor tip stall is established, that is, the aerodynamic throat appeared inside the flow passage, reducing the ability of the blade tip to withstand back pressure, and the low-speed areas caused by the tipleakage-vortex breakage and boundary layer separation reduced the flow capacity of the blade tip. Based on the reasons for rotor stall, three methods are proposed to improve the stall margin, which include increasing the exit radius of the upper meridian, forward sweep of the blade tip, and increasing the chord length of the blade tip. The above method is used to design a supersonic rotor with a total pressure ratio of 2.8 , which exhibits an efficiency of 0.902 at the design point and a stall margin of $18.11 \%$.
\end{abstract}

\section{Introduction}

Aeroengines are always designed to realize high thrustweight ratio and low fuel consumption. In an aeroengine, the compressor is heavy and has many stages. When the total pressure ratio is constant, increasing the single-stage pressure ratio can decrease the number of compressor stages, effectively reducing the size and weight of the engine. Over the years, compressor designers have continued to pursue the strategy of increasing the stage pressure ratio. Clearly, it would save weight and parts if the compressor could develop the same pressure ratio in as few compressor stages as possible [1]. The new generation of aeroengines developed by the US programs IHPTET and VAATE has a thrust-weight ratio of 15-20 [2]. Tests of an earlier version of the engine, a powerplant designated XTE-65/1, resulted in a thrust-to- weight improvement of $20 \%$ [3]; the entire fan is reduced to include just 1-2 stages, and the core compressor uses only 3-4 stages [4]. Over the past 50 years, the performance of a fan/compressor has improved significantly, which is mainly manifested as an enhancement in the single-stage pressure ratio, total pressure ratio, and efficiency, where the stall margin satisfies the design requirements. One of the main reasons for these advances is the continuous increase in the rotational speed, which can cause the inlet relative flow to develop into fully supersonic flow, and the corresponding compressor is called supersonic compressor.

The research on supersonic compressors began in the middle of the 20th century. In 1945, Kantrowitz and Donaldson [5] performed a preliminary investigation on a supersonic compressor; and in 1946, Kantrowitz [6] discussed some of the essential aerodynamics of single-stage supersonic 


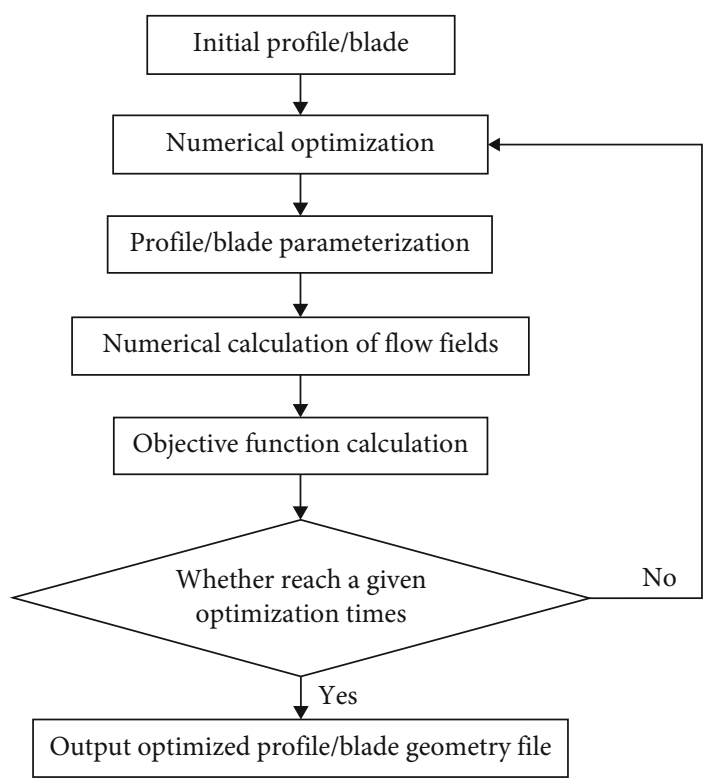

FIgURE 1: Automatic optimization design procedure.

axial-flow compressors further. In the earlier studies on supersonic compressor, the shock flow mechanism was not utilized fully, and the efficiencies of designed supersonic compressors were low due to the large shock loss. Further, since the supersonic compressors needed to use freon as the test gas, the research was interrupted due to the environmental limitations. After the 1990s, with the development of computational fluid dynamics (CFD) technology and advanced computer systems, numerical simulation of threedimensional (3D) viscous flow field could be used to accurately simulate the flow fields in supersonic compressors, which effectively improved the understanding of the shock flow mechanism in these compressors. Küsters and Schreiber [7] simulated the flow field of a supersonic cascade and proved that the numerical simulation results were basically consistent with the experimental results. Since then, several numerical simulation methods have been used to design supersonic compressors.

With the rapid advancement of computer technologies, the automatic optimization method has been gradually applied to the aerodynamic design of compressors. Benini [8] developed a multiobjective design optimization method for transonic compressor design and applied to redesign the NASA rotor 37. Lian and Liou [9] developed an efficient approach for computationally expensive multiobjective design optimization problems. In their approach, the design of the experiment, a response surface model, a genetic algorithm, and computational-fluid-dynamics analysis tools were combined together to provide an integrated optimization system. Pan et al. [10] developed a multiobjective optimization methodology, which were based on the Kriging model, the physical programming method, and improved particle swarm optimization algorithm, and applied to achieve the multiobjective optimization of the supersonic tandem rotor blades. These methods combine numerical optimization with numerical calculation of flow fields. It replaces human work with mathematical operation, controls the modification direction of blade design, and significantly reduces the dependence on personnel experience and shortens the design cycle. Because supersonic flow is particularly sensitive to the variation in blade shape, the automatic optimization method is suitable for the design of a two-dimensional (2D) supersonic profile and 3D blade. For example, Venturelli and Benini [11] optimized a 2D supersonic compressor cascade using the multiobjective optimization method, and the total pressure loss coefficient of the optimized profile was $25 \%$ lower than that of the original profile.

Stall margin is an important performance parameter for the nondesign point of a compressor. In the numerical calculation of flow field in a compressor, the stall point is determined by manually increasing the outlet pressure gradually. It is difficult to determine the stall point using an automatic optimization process as the calculation of flow field is automated.

In this study, an automatic optimization method is proposed to design the $2 \mathrm{D}$ profiles and $3 \mathrm{D}$ blades for constructing a supersonic compressor rotor of a turboshaft engine with an aim at achieving high efficiency at the design point. Subsequently, the cause of stall initiation for the optimized supersonic rotor is analyzed. Further, the influence of the blade tip sweep, chord length of blade tip, and meridian flow path on the stall margin is examined. A substantial improvement in the stall margin of a supersonic rotor is achieved by modifying the above parameters.

\section{Aerodynamic Design of Supersonic Compressor Rotor}

The aerodynamic design process of a supersonic compressor rotor based on the proposed optimization method is as follows:

(1) According to the given meridian flow path, rotational speed, and total pressure ratio, the throughflow design of the S2 flow surface is performed by using the streamline curvature method. The distribution of the inlet and outlet parameters along the blade height is obtained and used as the boundary conditions for the design of the 2D profile on the S1 surface (rotating surface)

(2) Initial 2D profiles are designed for the next optimization design of the $2 \mathrm{D}$ profile

(3) The initial $2 \mathrm{D}$ profiles are optimized by using a $2 \mathrm{D}$ profile optimization method

(4) The optimized 2D profiles are stacked in the radial direction to form the original 3D blade

(5) The original 3D blade is optimized by using a 3D blade optimization method

2.1. Optimization Design Method of $2 D$ Profiles and $3 D$ Blades. The optimization design of 2D profiles and 3D blades is based on a self-developed automatic optimization design software $[12,13]$. The optimization design software mainly 


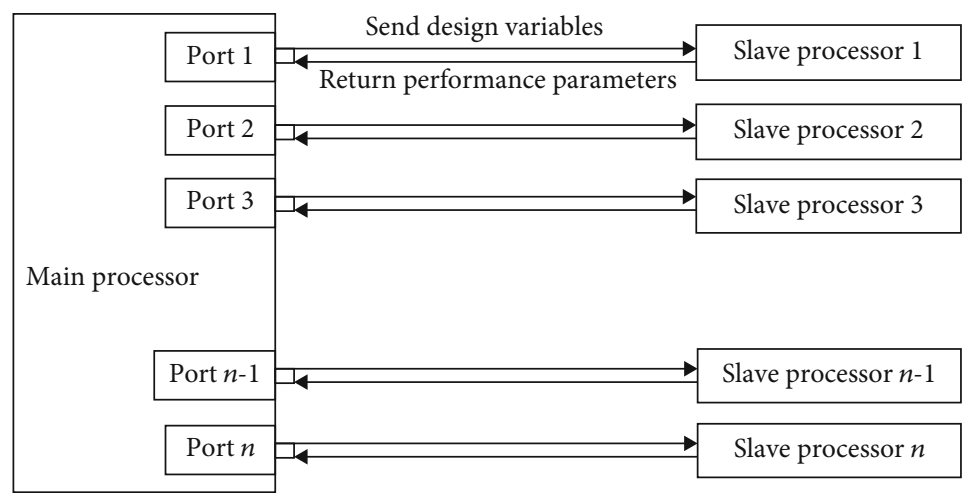

FIGURE 2: Block diagram of parallel communication in the genetic algorithm optimization process.

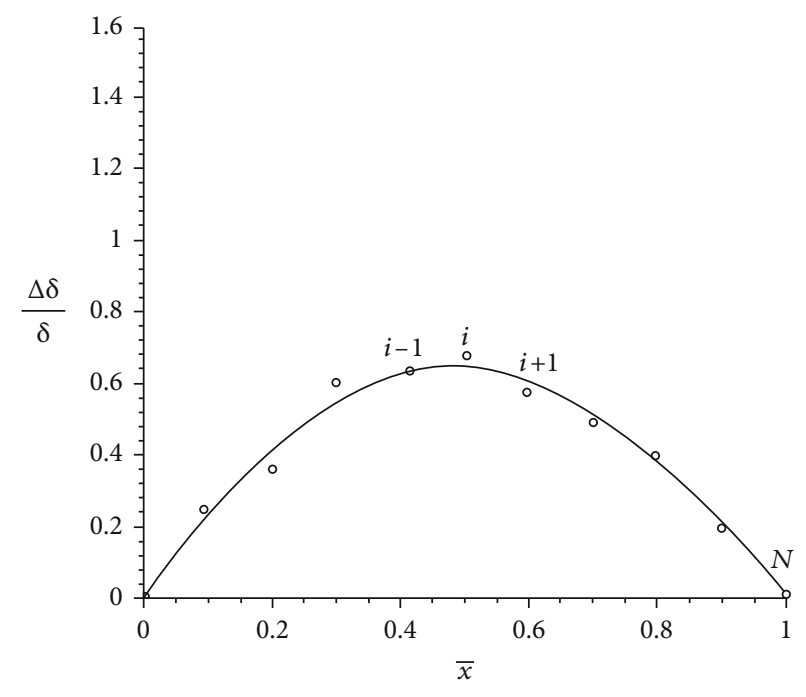

(a)

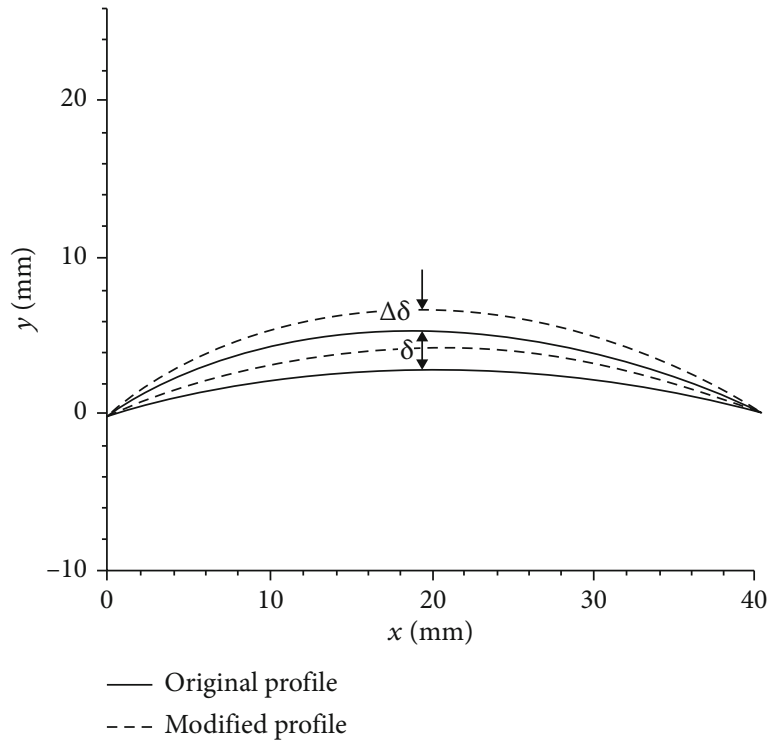

(b)

FIgURE 3: Outline of 2D profile parameterization.
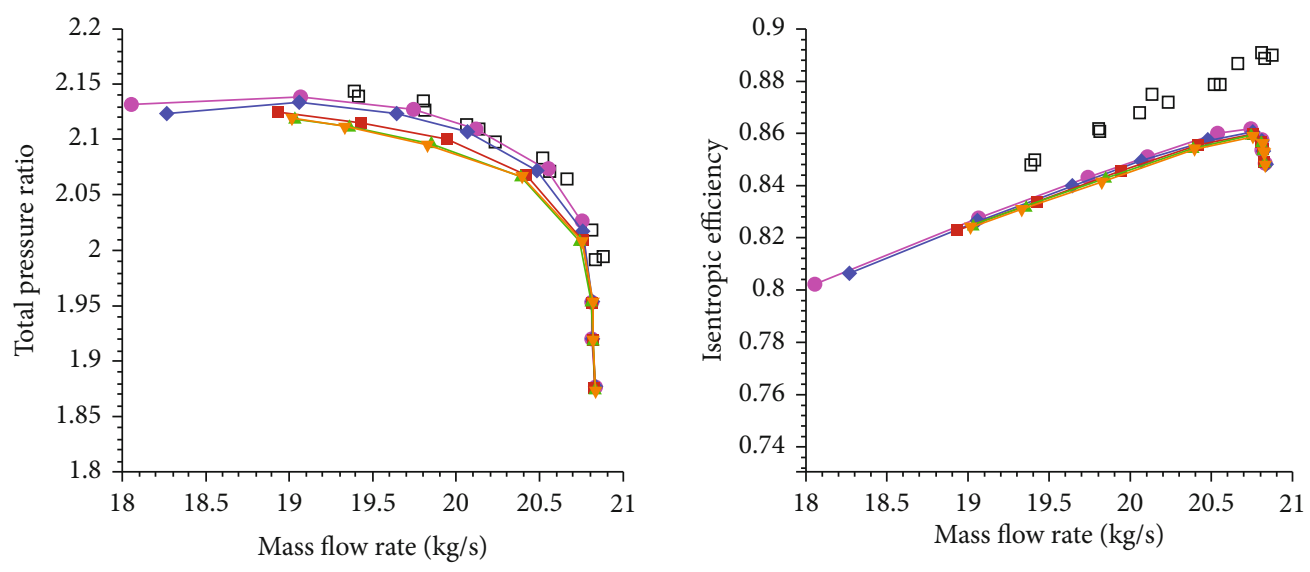

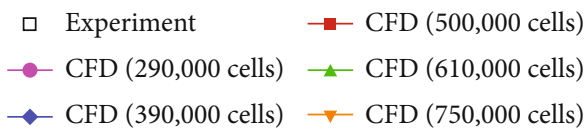

Figure 4: Performance curves of NASA Rotor 37. 
TABLE 1: Main parameters of supersonic rotor.

\begin{tabular}{lc}
\hline Parameters & Value \\
\hline$\pi_{k, d}^{*}$ & 2.80 \\
$\eta_{k, d}^{*}$ & $\geq 0.89$ \\
$\mathrm{SM}$ & $\geq 15 \%$ \\
$\dot{m}_{d}(\mathrm{~kg} / \mathrm{s})$ & $6.35 \mathrm{~kg} / \mathrm{s}$ \\
$\bar{H}$ & 0.383 \\
$N(\mathrm{rpm})$ & $45000 \mathrm{rpm}$ \\
$U(\mathrm{~m} / \mathrm{s})$ & $471 \mathrm{~m} / \mathrm{s}$ \\
$\mathrm{Ma}_{1, \mathrm{root}}$ & 1.08 \\
$\mathrm{Ma}_{1, \mathrm{tip}}$ & 1.62 \\
$\sigma(\mathrm{mm})$ & $0.2 \mathrm{~mm}$ \\
\hline
\end{tabular}

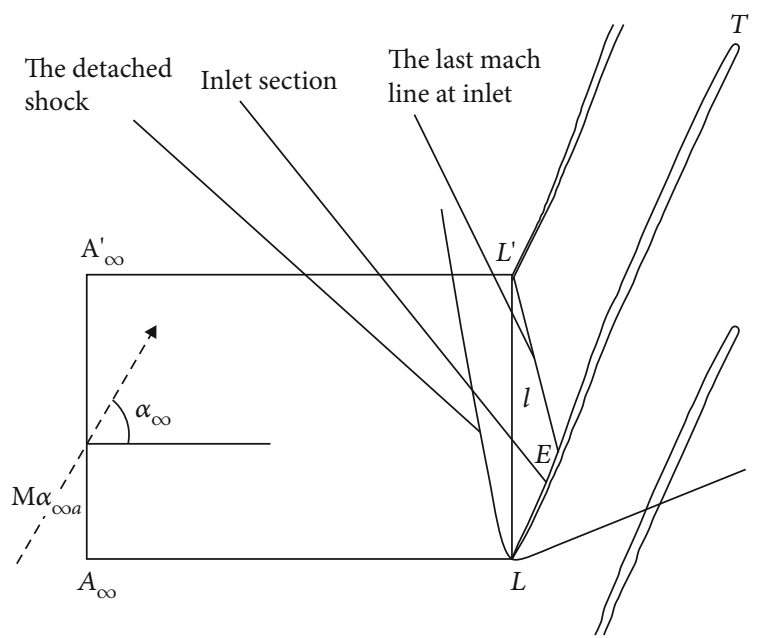

FIGURE 5: Flow characteristics of inlet section in the supersonic cascade.

includes a numerical optimization module, a module for numerical calculation of flow field, parameterization module for $2 \mathrm{D}$ profile and 3D blade, and an objective function setting module. Figure 1 shows the automatic optimization design procedure of $2 \mathrm{D}$ profiles and 3D blades.

2.2. Numerical Optimization Method. In this study, the genetic algorithm [14] is used for the numerical optimization module in the automatic optimization design software. This optimization method has the ability of global optimization, but the attainment of global optimum primarily depends on the size of search space and the number of individuals in the population. The smaller the search space and the larger the number of individuals, the greater the probability of finding the global optimum. For a given search space, the higher the number of individuals, the greater the probability of finding the global optimum. For the optimization of a 2D profile and $3 \mathrm{D}$ blade, the value of the objective function must be obtained from the results of flow field calculations. Therefore, the greater the number of individuals, the longer the time required for optimization. Compared to $2 \mathrm{D}$ blade profile
TABLE 2: Variable range for 2D profile optimizations.

\begin{tabular}{lccc}
\hline \multicolumn{2}{c}{ Suction surface } & \multicolumn{2}{c}{ Pressure surface } \\
Position & Range & Position & Range \\
\hline 0 & {$[-0.5,0.5]$} & 0 & {$[-0.5,0.5]$} \\
0.15 & {$[-0.5,0.5]$} & 0.15 & {$[-0.5,0.5]$} \\
0.30 & {$[-0.5,0.5]$} & 0.30 & {$[-0.5,0.5]$} \\
0.50 & {$[-0.5,0.5]$} & 0.50 & {$[-0.5,0.5]$} \\
0.70 & {$[-0.5,0.5]$} & 0.70 & {$[-0.5,0.5]$} \\
0.85 & {$[-0.5,0.5]$} & 0.85 & {$[-0.5,0.5]$} \\
1.00 & {$[-0.5,0.5]$} & 1.00 & {$[-0.5,0.5]$} \\
\hline
\end{tabular}

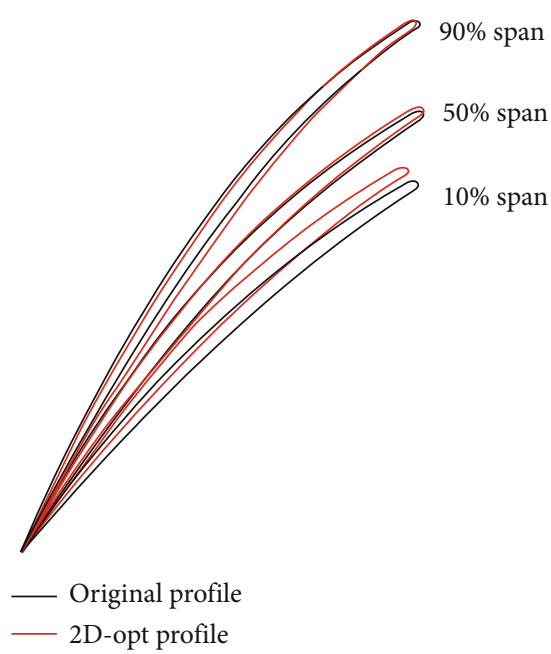

Figure 6: Comparison between the initial and optimized profiles.

TABle 3: Comparison between performances of the original and optimized profiles.

\begin{tabular}{ccccccc}
\hline Span & & $\mathrm{Ma}_{1}$ & $\beta_{1}(\mathrm{deg})$ & $\pi_{k, p}^{*}$ & $\pi_{s, p}$ & $\eta_{k, p}^{*}$ \\
\hline \multirow{3}{*}{$10 \%$} & Target & 1.13 & 55.8 & 2.80 & 2.05 & 0.900 \\
& Initial & 1.10 & 59.8 & 2.78 & 1.84 & 0.910 \\
& Optimal & 1.14 & 57.3 & 2.79 & 1.94 & 0.931 \\
\multirow{3}{*}{$50 \%$} & Target & 1.35 & 61.6 & 2.80 & 2.23 & 0.900 \\
& Initial & 1.30 & 67.6 & 2.75 & 1.86 & 0.853 \\
& Optimal & 1.32 & 63.0 & 2.78 & 1.91 & 0.904 \\
\multirow{2}{*}{$90 \%$} & Target & 1.57 & 66.2 & 2.80 & 2.46 & 0.900 \\
& Initial & 1.59 & 67.5 & 2.77 & 2.18 & 0.884 \\
& Optimal & 1.59 & 66.8 & 2.80 & 2.21 & 0.910 \\
\hline
\end{tabular}

optimization, 3D blade optimization includes more variables, so the optimization space is much larger and the number of individuals in the population must also be larger. In addition, the calculation of the 3D flow field is more time consuming. Therefore, it takes much longer to optimize a 3D blade than to optimize a $2 \mathrm{D}$ profile.

To reduce the time required for $3 \mathrm{D}$ blade optimization in the genetic algorithm, the inherent parallel characteristics of the genetic algorithm are utilized to realize parallel 
TABLE 4: Variable position and range for 3D blade optimizations.

\begin{tabular}{|c|c|c|c|c|c|}
\hline \multicolumn{2}{|c|}{ The central arc of the profile } & \multicolumn{2}{|c|}{ Chord length } & \multicolumn{2}{|c|}{ Profile installation angle } \\
\hline $\begin{array}{l}\text { Relative chord } \\
\text { position }\end{array}$ & $\begin{array}{c}\text { Range/relative maximum } \\
\text { thickness }\end{array}$ & $\begin{array}{c}\text { Position/relative blade } \\
\text { height }\end{array}$ & $\begin{array}{c}\text { Range/relative chord } \\
\text { length }\end{array}$ & $\begin{array}{c}\text { Position/relative blade } \\
\text { height }\end{array}$ & Range/degree \\
\hline 0 & {$[-0.5,0.5]$} & 0 & {$[-0.1,0.1]$} & 0 & {$[-3.0,3.0]$} \\
\hline 0.25 & {$[-0.5,0.5]$} & 0.25 & {$[-0.1,0.1]$} & 0.25 & {$[-2.5,2.5]$} \\
\hline 0.50 & {$[-0.5,0.5]$} & 0.50 & {$[-0.1,0.1]$} & 0.50 & {$[-2.0,2.0]$} \\
\hline 0.75 & {$[-0.5,0.5]$} & 0.75 & {$[-0.1,0.1]$} & 0.75 & {$[-1.5,1.5]$} \\
\hline 1.00 & {$[-0.5,0.5]$} & 1.00 & {$[-0.1,0.1]$} & 1.00 & {$[-1.0,1.0]$} \\
\hline
\end{tabular}

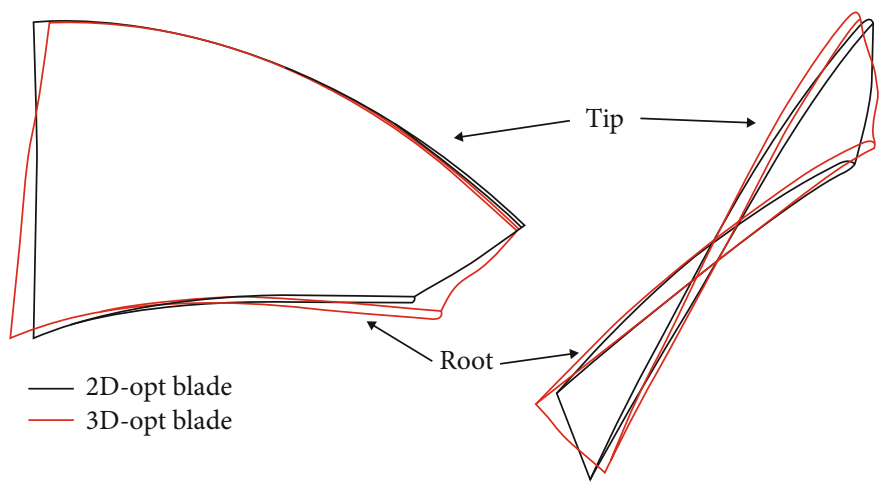

Figure 7: Blade shape before and after the optimization.

optimization based on the network communication protocol. The basic principle of this method is as follows. Using a local area network composed of multiple computers or the network of a computer cluster, each individual generation of the genetic algorithm is grouped according to the number of computers in the network, and all groups of individuals are distributed to the corresponding computer for the flow field calculations. Then, the corresponding computer returns the calculated aerodynamic performance parameters (total pressure ratio, mass flow rate, efficiency, etc.). Since the amount of data being transmitted during the optimization process is small and the time spent in the data transmission is very short relative to the flow field calculations, the time required for the optimization is approximately inversely proportional to the number of computers participating in the optimization process. Figure 2 shows a block diagram of parallel communication in the genetic algorithm optimization process.

2.3. Parameterization Method for $2 D$ Profile and $3 D$ Blade. A $3 \mathrm{D}$ compressor blade is composed of several $2 \mathrm{D}$ profiles stacked in radial direction according to a certain stacking rule. Therefore, the parameterization of a 3D blade is essentially based on that of the $2 \mathrm{D}$ profile, including the parameterization of stacking line and meridional flow path. The $2 \mathrm{D}$ profile and meridian flow path are represented by $2 \mathrm{D}$ curves, while the stacking lines of blade are characterized by $3 \mathrm{D}$ curves. However, the stacking lines can be decomposed into two 2D curves for parameterization, namely, lean and sweep. Therefore, 3D blade parameterization is essentially a combination of several 2D curve parameterization.
TABLE 5: Aerodynamic performance of the three rotors at the design point.

\begin{tabular}{lccc}
\hline Parameters & Original rotor & 2D-opt rotor & 3D-opt rotor \\
\hline$\dot{m}_{d}(\mathrm{~kg} / \mathrm{s})$ & 6.35 & 6.37 & 6.37 \\
$\pi_{k, d}^{*}$ & 2.80 & 2.80 & 2.80 \\
$\eta_{k, d}^{*}$ & 0.877 & 0.894 & 0.910 \\
$\mathrm{SM}(\%)$ & 9.41 & 2.71 & 1.59 \\
\hline
\end{tabular}

The 2D profile can be divided into suction surface and pressure surface lines from the leading and trailing edge points. Here, the profile parameterization method based on the modification amount is adopted, i.e., the modification amount is superimposed on the original profile line, where the modification amount is described by the Bezier curve, and the local thickness of the profile is considered to be dimensionless. As shown in Figure 3(a), the modification position $\overline{\mathrm{x}}$ represents the direction of the dimensionless chord line, where the interval, leading edge, and trailing edge are $[0,1], 0$, and 1 , respectively. The local thickness of the shape is $\delta$, the thickness modification is $\Delta \delta$, and the dimensionless modification is $\Delta \delta / \delta$. In Figure 3(a), the distribution of modification amount along the $x$-axis is expressed by a Bezier curve, which is determined by the $N$ modification positions and the corresponding dimensionless modification values. The modified profile is obtained by superimposing the distribution of the modification amount on the original profile (Figure 3(b)). Here, the modification positions are the specified parameters, and the corresponding 


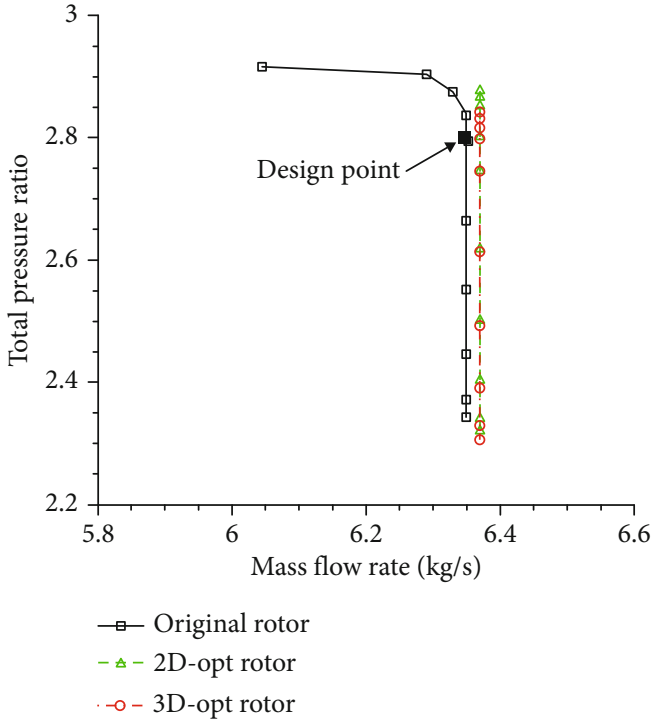

(a) Mass flow rate vs. total pressure ratio

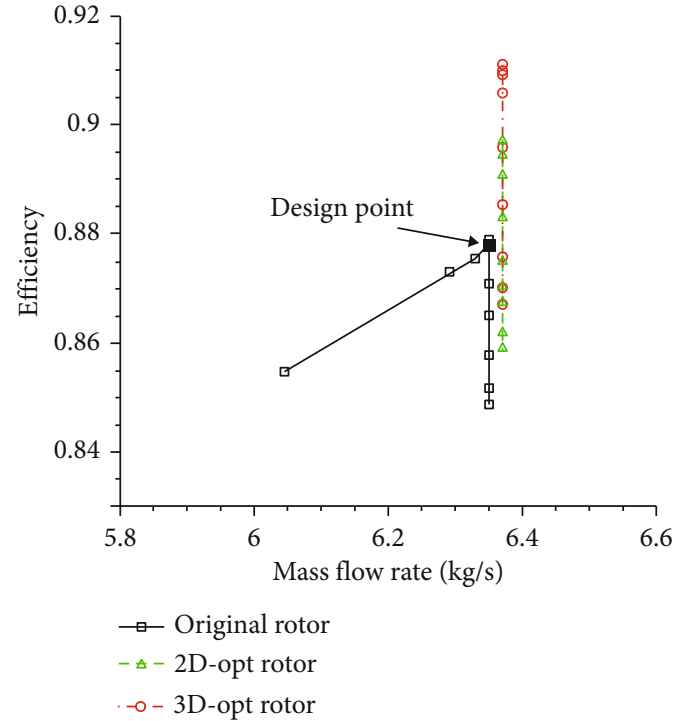

(b) Mass flow rate vs. efficiency

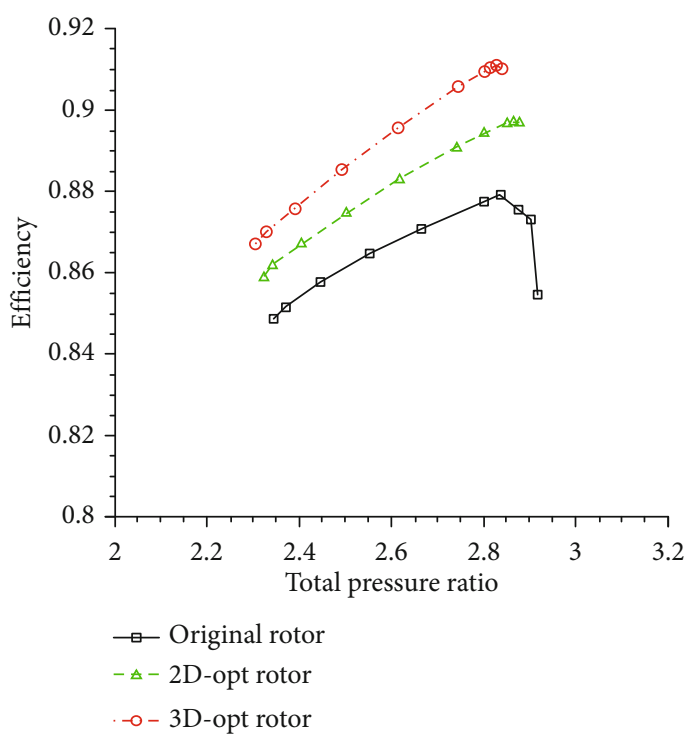

(c) Total pressure ratio vs. efficiency

FIgURE 8: Performance curves for the three rotors.

dimensionless modification values are the design variables. The parameterization method of the stacking line sweep for the 3D blade and meridian flow path are the same as that for $2 \mathrm{D}$ profile lines.

2.4. Setting the Objective Function. For optimized design of $2 \mathrm{D}$ profiles, the objective function $F$ is constructed according to equation (1), and the optimization process is aimed at obtaining the maximum value of $F$.

$$
F=c_{1} \eta_{k}^{*}+c_{2}\left(1-\frac{\left|\pi_{k}^{*}-\pi_{k, \mathrm{obj}}^{*}\right|}{\pi_{k, \mathrm{obj}}^{*}}\right)+c_{3}\left(1-\frac{\left|\pi_{s}-\pi_{s, \mathrm{obj}}\right|}{\pi_{s, \mathrm{obj}}}\right),
$$

where $c_{1}, c_{2}$, and $c_{3}$ are the weight coefficients; $\pi_{k, \text { obj }}^{*}$ and $\pi_{s, \text { obj }}$ are the target total pressure ratio and static pressure ratio of the $2 \mathrm{D}$ rotating surface cascade at the design point, respectively. This setting of the objective function is used to maximize the efficiency under the premise of achieving the given total pressure ratio and static pressure ratio at the design point. The objective values of total and static pressure ratio are determined by the throughflow design. In fact, the static pressure ratio is considered the design goal to ensure that the inlet Mach number of the cascade reaches a given value. The weight coefficients are set empirically. Generally, it is easier to achieve the desired total and static pressure ratio, but it is difficult to improve the efficiency. Therefore, the value of $c_{1}$ should be greater than the values of $c_{2}$ and $c_{3}$. 


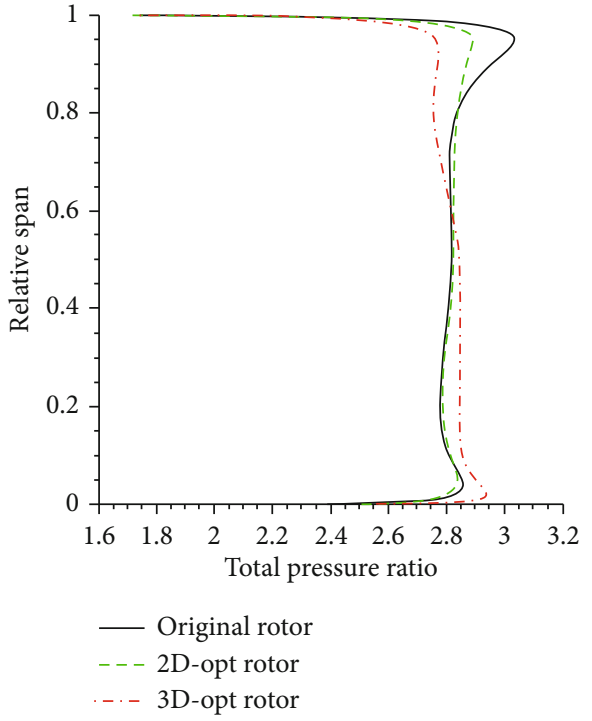

(a)

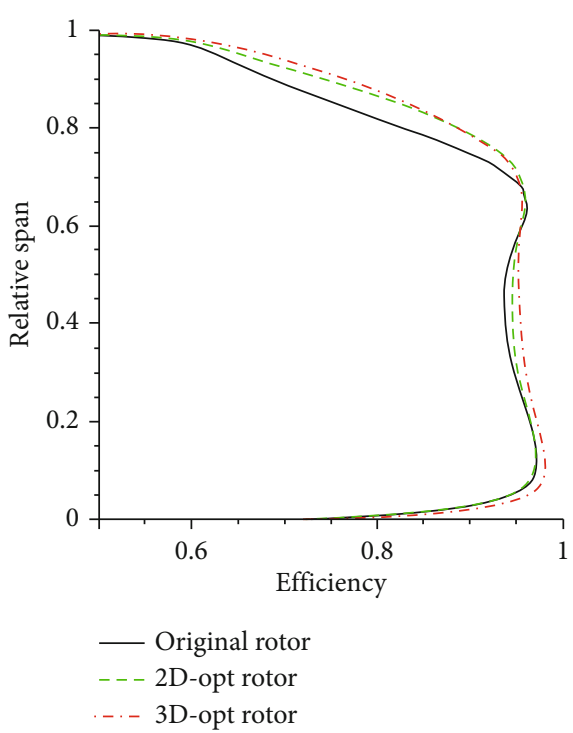

(b)

FIgURE 9: Radial distribution of average outlet tangential parameters at the design point.

The initial values can be set as $c_{1}=100, c_{2}=10$, and $c_{3}=10$. Subsequently, it is determined whether the weight coefficients must be adjusted according to the optimization results and then the optimization is performed again. For example, if the total pressure ratio is quite different from the target value, then the value of $c_{2}$ can be increased while reoptimizing. While reoptimizing, the previously optimized profile can be used as the original profile.

For an optimized design of the 3D blades, the objective function is constructed as follows:

$$
F=c_{1} \eta_{k}^{*}+c_{2}\left(1-\frac{\left|\dot{m}-\dot{m}_{\mathrm{obj}}\right|}{\dot{m}_{\mathrm{obj}}}\right)+c_{3}\left(1-\frac{\left|\pi_{k}^{*}-\pi_{k, \mathrm{obj}}^{*}\right|}{\pi_{k, \mathrm{obj}}^{*}}\right),
$$

where $c_{1}, c_{2}$, and $c_{3}$ are the weight coefficients; $\dot{m}_{\mathrm{obj}}$ and $\pi_{k, \mathrm{obj}}^{*}$ are the target mass flow rate and total pressure ratio of the rotor at the design point, respectively. The objective function is set to maximize the efficiency $\eta_{k}^{*}$ under the premise of reaching the given mass flow rate and total pressure ratio at the design point. Therefore, the initial values can be set as $c_{1}=100, c_{2}=10$, and $c_{3}=10$. Then, it is determined whether the weight coefficient should be adjusted according to the optimization result, and the optimization is repeated.

While setting the objective function for the optimization design of 2D profiles and 3D blades, only the performance at the design point is considered and that at the nondesign point is not considered. In this way, it is necessary to calculate the flow field just at the design point and is not at the nondesign point, which greatly reduces the time consumed in the optimization process, especially for the optimization design of $3 \mathrm{D}$ blades. After the optimization of the 3D blade, the per- formance of the rotor at the nondesign point (namely, the stall margin) is improved artificially.

2.5. Numerical Calculation of Flow Fields. The numerical calculation of both 2D flow fields in the rotary surface cascades and the 3D flow fields in the rotors was based on the script files that called the grid generation module AUTOGRID and the numerical calculation module FINE of the commercial software Numeca, and the optimization parameters such as mass flow rate, efficiency, and total pressure ratio were obtained from the numerical calculation results. To numerically solve the Navier-Stokes equations, the Spalart-Allmaras (SA) turbulence model was used, and the second-order central difference was utilized for spatial discretization.

To validate the CFD method, the flow field in the NASA Rotor 37 [15] was calculated, and the calculated and experimental results were compared. $\mathrm{O} 4 \mathrm{H}$ was employed as the grid type, and the total number of grid nodes was selected for flow field calculation. Figure 4 shows that grid independence can be achieved when the grid size is nearly 500,000. Therefore, this grid was used to calculate the 3D flow field of the supersonic rotors in the optimization process.

\section{Aerodynamic Design of Supersonic Compressor Rotor}

The above optimization method was applied for the aerodynamic design of the first-stage supersonic rotor in an axial compressor of a turboshaft engine. The inlet flow was considered to be axial; equal circulation distribution law was adopted, i.e., the total pressure ratio along the blade height was constant. Table 1 shows the main parameters of the rotor, where $\pi_{k, d}^{*}, \eta_{k, d}^{*}$, and $\dot{m}_{d}$ are total pressure ratio, efficiency, and mass flow rate, respectively. 

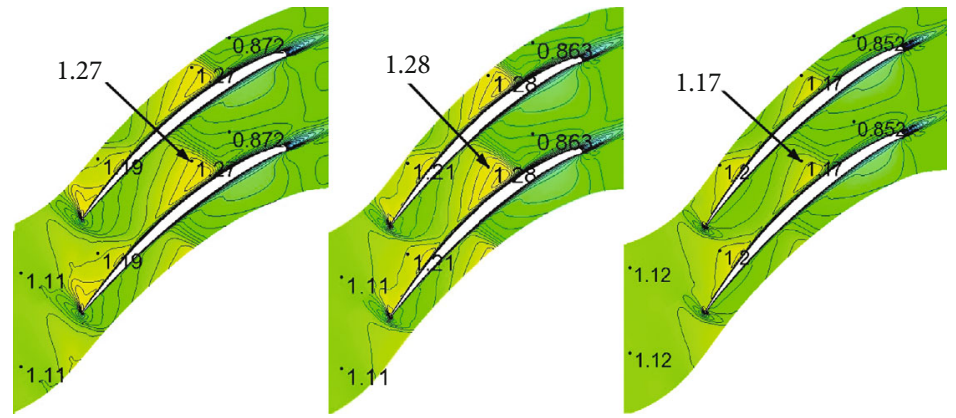

(a) $10 \%$ span
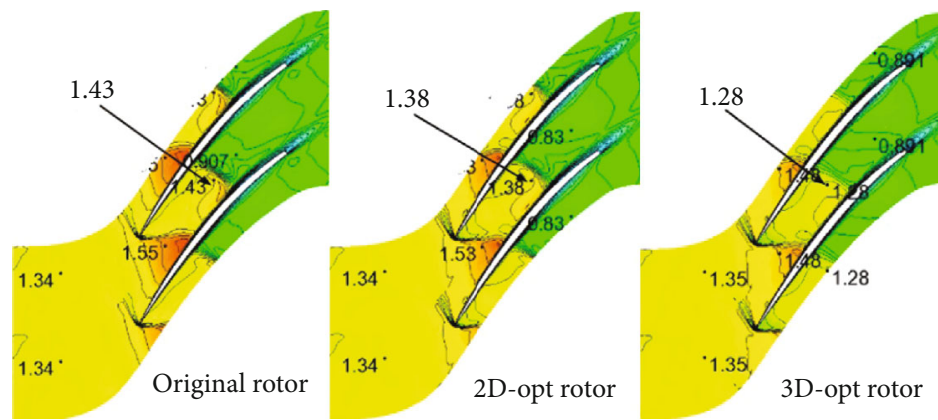

(b) $50 \%$ span
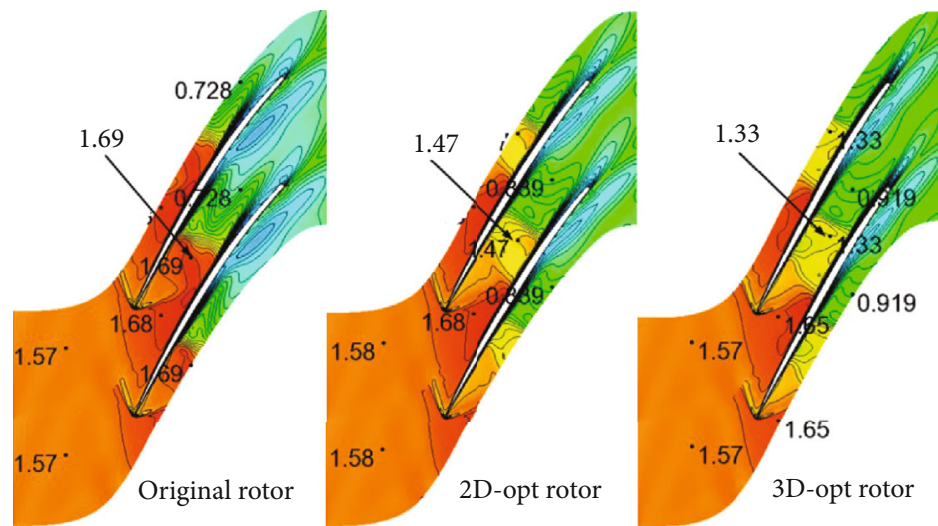

(c) $90 \%$ span
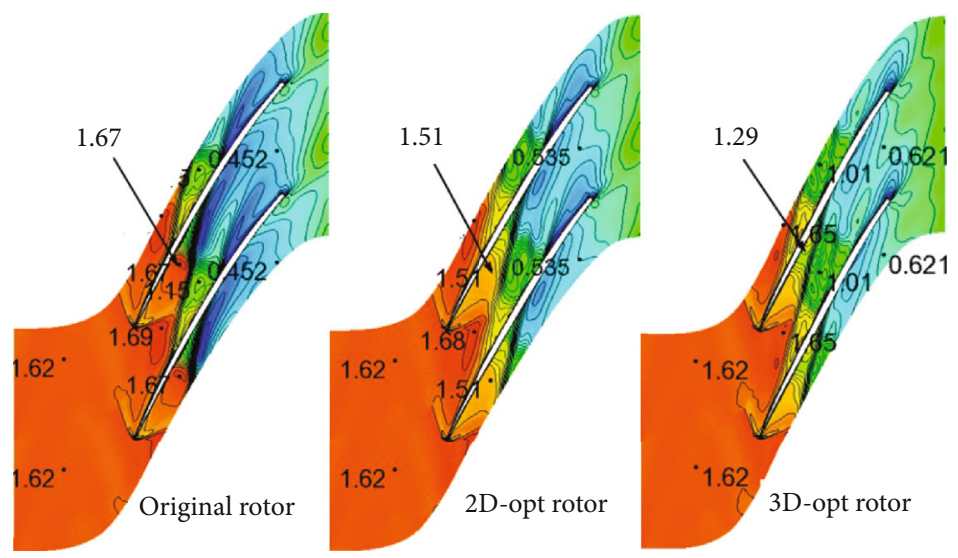

(d) $99 \%$ span

FigURE 10: Mach number contours of the three rotors at the design point. 


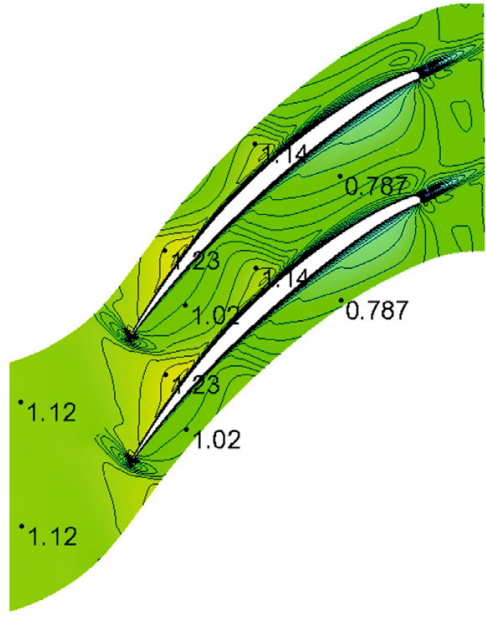

(a) $10 \%$ span

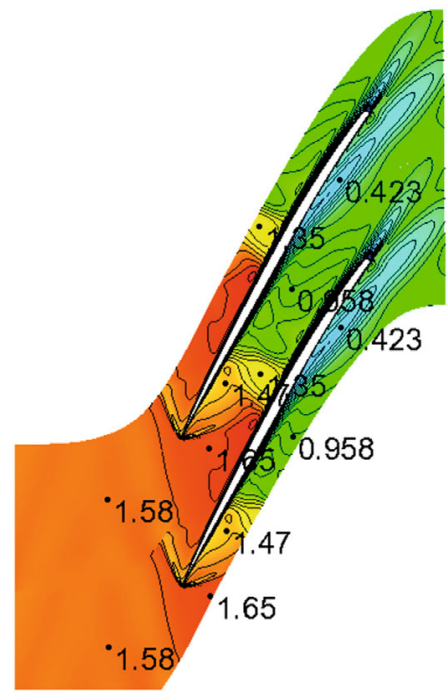

(c) $90 \%$ span

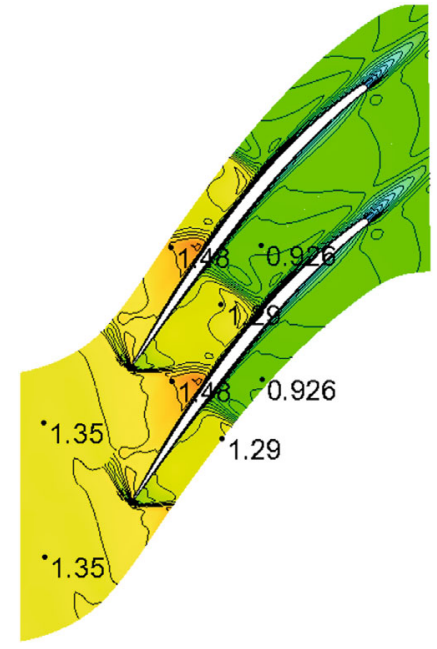

(b) $50 \%$ span

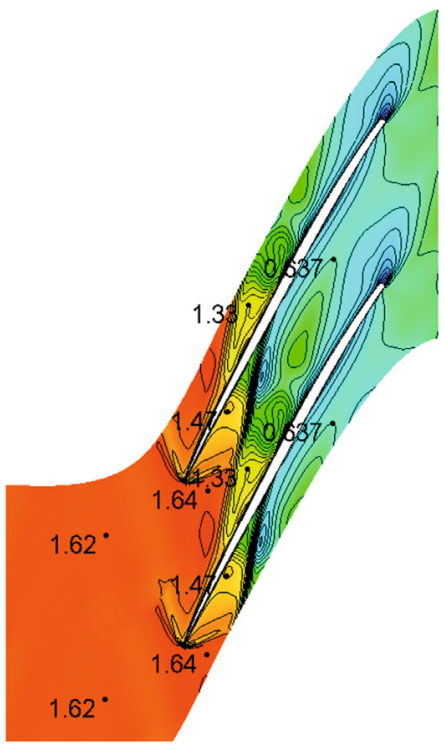

(d) $99 \%$ span

Figure 11: Mach number contours of 3D-opt rotor at stall point on S1 surfaces.

3.1. Optimization Design of 2D Blade Profiles. Because the parameterization method based on the modification amount is applied, it is necessary to initially construct the initial $2 \mathrm{D}$ profiles. In Figure 5, according to the simple wave relation of supersonic flow and the mass flow rate at the far upstream section $A_{\infty} A^{\prime}{ }_{\infty}$ and the last Mach line $E L^{\prime}$ of the inlet, the inlet Mach number and flow angle of the cascade are determined by the position and slope of point $E$ on the suction surface, which is the unique inlet flow angle of the supersonic cascade $[14,16]$. The position and tangent angle of point $E$ on the suction surface are determined according to the inlet Mach number and flow angle. Point $E$ divides the suction surface of a supersonic profile into two sections: $L E$ and $E T$ sections. The Bezier curve is utilized to ensure the derivative continuity at the $E$ point. Then, the pressure surface is constructed by superimposing a thickness distribution on the suction surface.
According to the throughflow design results of supersonic rotor, the above design method is used to design the supersonic profiles at $10 \%, 50 \%$, and $90 \%$ spans. Further, these profiles are taken as the initial profiles for $2 \mathrm{D}$ profile optimization. In the optimization process, the chord length, installation angle, suction surface lines, and pressure surface lines of the $2 \mathrm{D}$ profile are considered the design parameters. The value ranges of the variables and the positions on the two surfaces of the $2 \mathrm{D}$ profile are shown in Table 2 . The range of the chord length for the initial profile is $[-0.1,0.1]$, and the range of installation angle is $\left[-5^{\circ}, 5^{\circ}\right]$. There are a total of 14 design variables in the optimization, and the number of individuals in the population is set to 112 in the genetic algorithm. In a computer cluster, 8 nodes (7 CPU per node) participate in the optimization. Each optimization sends 14 individuals to each node, and the optimization of 30 generations is completed in nearly $10 \mathrm{~h}$. 


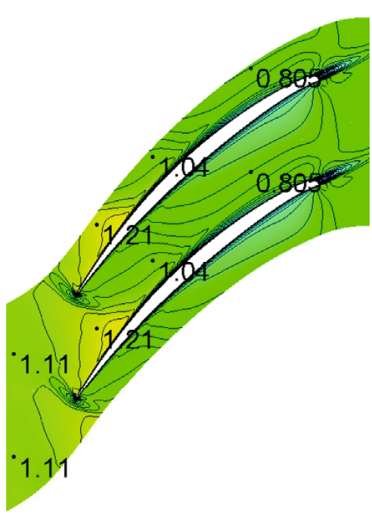

3900 steps

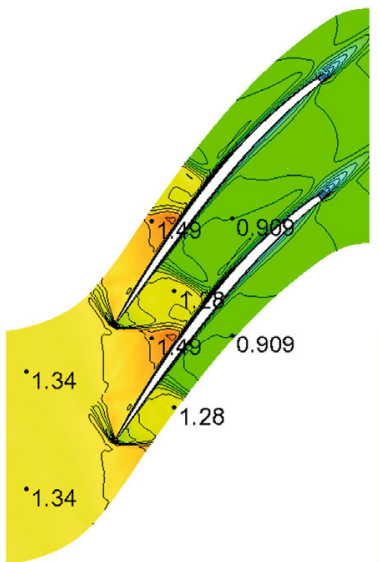

3900 steps

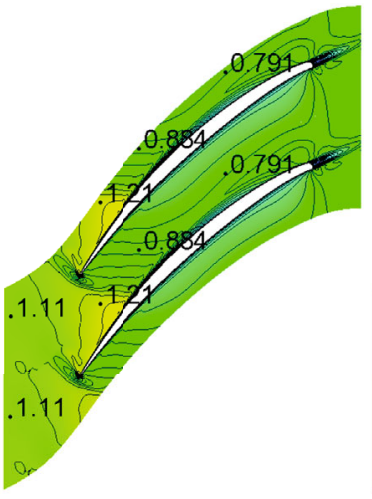

4200 steps

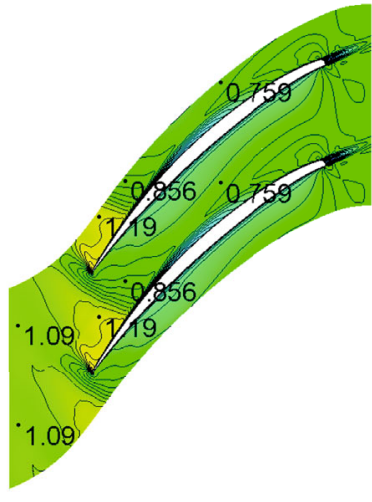

4600 steps

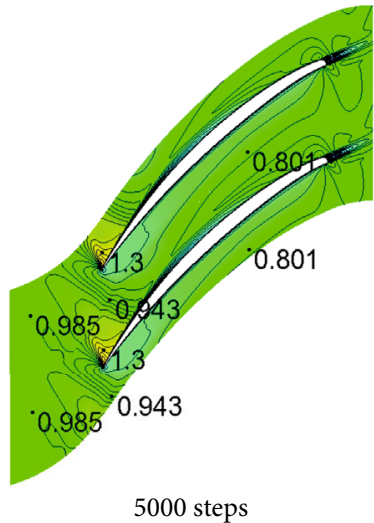

(a) $10 \%$ span

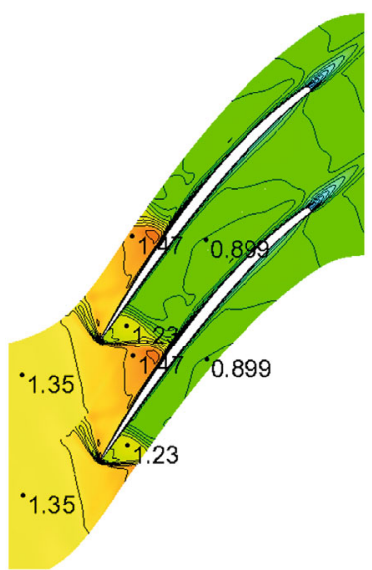

4200 steps

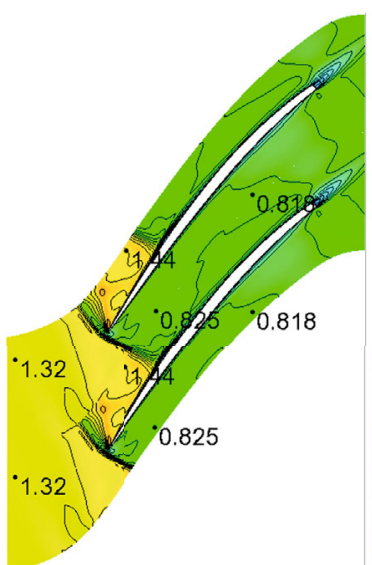

4600 steps

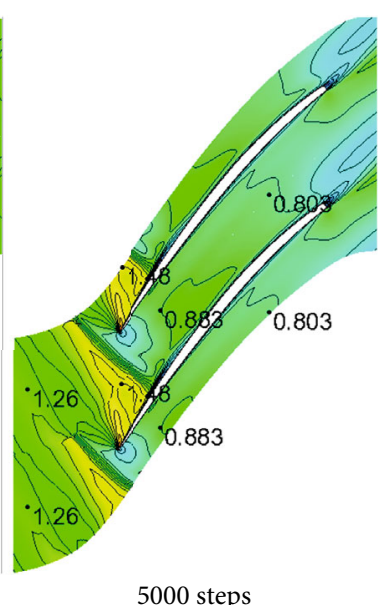

5000 steps

(b) $50 \%$ span

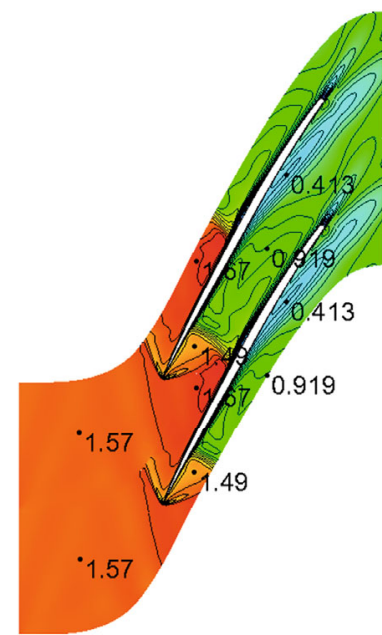

3900 steps

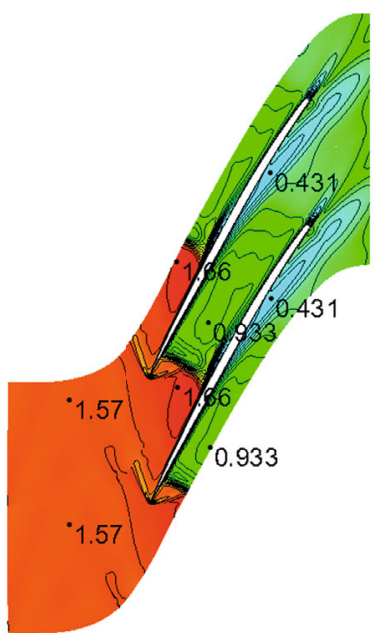

4200 steps

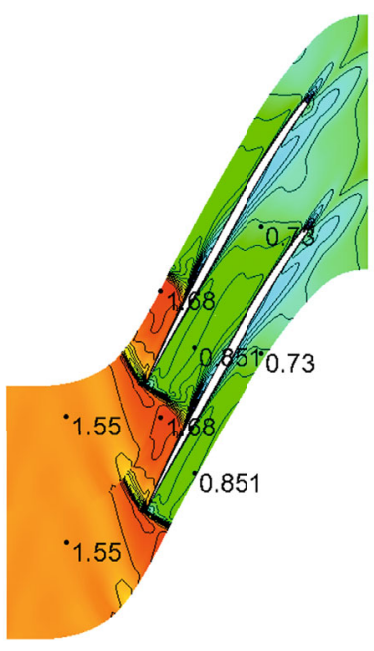

4600 steps

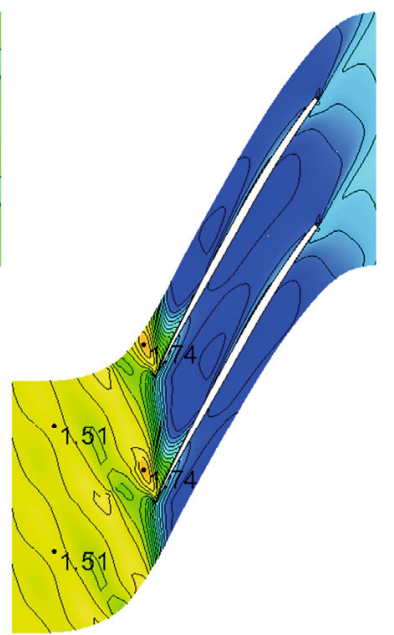

5000 steps

(c) $90 \%$ span

Figure 12: Stall development of the 3D-opt rotor.

Figure 6 shows a comparison between the initial and optimized profiles. $\pi_{k, p}^{*}, \pi_{s, p}$, and $\eta_{k, p}^{*}$ in Table 3 represent the total pressure ratio, static pressure ratio, and efficiency of the cascade on the rotating surface at the design point. It is clear from Table 3 that the inlet Mach numbers of the initial profiles are in excellent agreement with the target values (S2 throughflow design values), and the differences in inlet flow angles are slightly larger. After the optimizations, the 


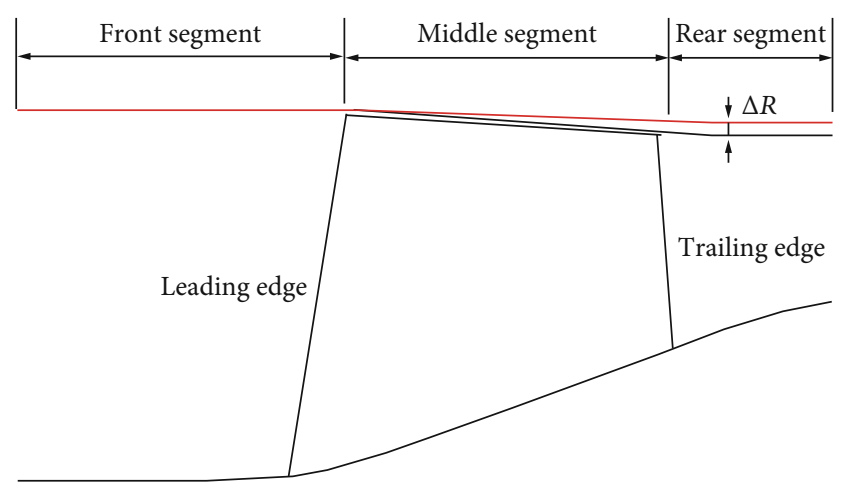

- Original shroud

— Modified shroud

Figure 13: Schematic for the expansion of upper meridian plane.

TABle 6: Aerodynamic performance of five rotors.

\begin{tabular}{lcccc}
\hline & $\dot{m}_{d}(\mathrm{~kg} / \mathrm{s})$ & $\pi_{k, d}^{*}$ & $\eta_{k, d}^{*}$ & SM (\%) \\
\hline 3D-opt rotor & 6.37 & 2.80 & 0.910 & 1.59 \\
Shroud+1 mm & 6.37 & 2.80 & 0.901 & 3.52 \\
Shroud+2 mm & 6.38 & 2.80 & 0.895 & 4.77 \\
Shroud+3 mm & 6.38 & 2.80 & 0.888 & 5.78 \\
Shroud+4 mm & 6.38 & 2.80 & 0.880 & 8.95 \\
\hline
\end{tabular}

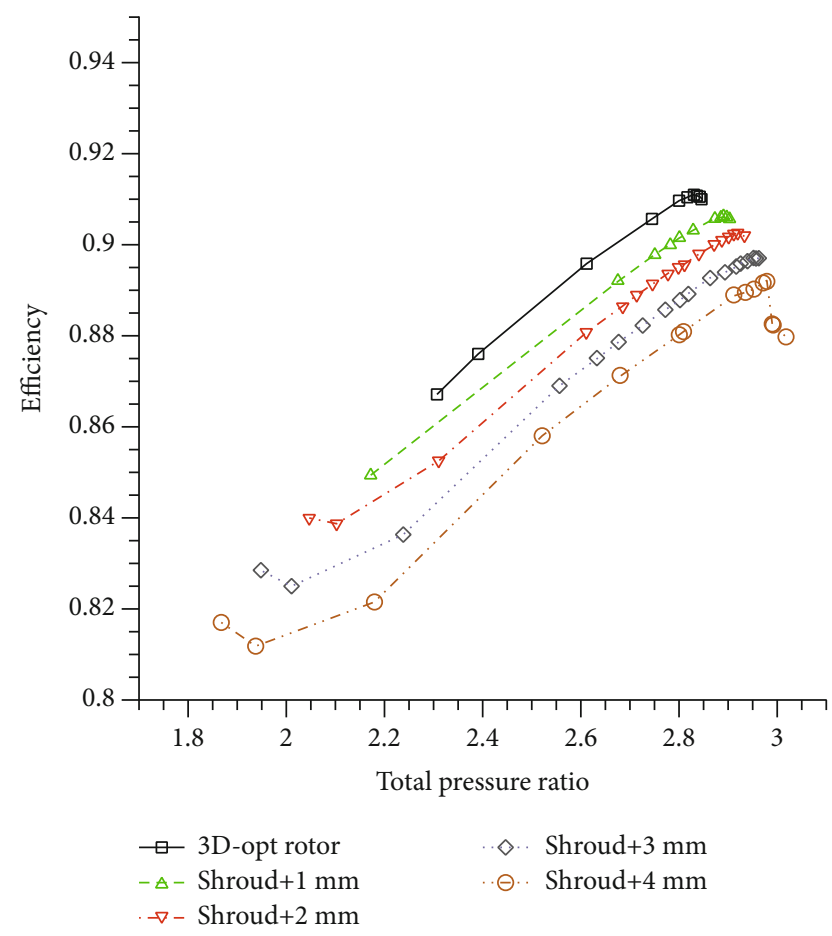

FIGURE 14: Relationship between total pressure ratio and efficiency for the five rotors.

inlet Mach numbers, inlet flow angles, and total and static pressure ratios become closer to the target values, and the efficiencies are also significantly higher than the initial values.
The initial profiles are stacked along the radial direction to form a blade called the original blade (corresponding to original rotor). The optimized profiles are stacked along the radial direction to form a blade called $2 \mathrm{D}$-opt blade (corresponding to $2 \mathrm{D}$-opt rotor). The $2 \mathrm{D}$-opt blade is used as the original blade for subsequent $3 \mathrm{D}$ optimization, and the 3D optimized blade is called 3D-opt blade (corresponding to $3 \mathrm{D}$-opt rotor). For the sake of clarity, after completing the 3D optimization, the three types of blades are compared.

3.2. Optimization Design of $3 D$ Blade. For optimization design of $3 \mathrm{D}$ blade, five profiles at $0 \%, 30 \%, 60 \%, 80 \%$, and $100 \%$ spans are selected to be optimized in the 3D flow field. Five modification positions are uniformly distributed on the central arc of the profiles (the thickness distribution is not modified). The value ranges of the variables and the positions are shown in Table 4 . There are a total of 35 design variables, which include five profile installation angles and five chord length modification variables. The number of individuals in the population of genetic algorithm is set to 448 . In the computer cluster, 8 nodes (7 CPUs per node) participate in the optimization. Each optimization process sends 56 individuals to each node, and the optimization of 24 generations is completed in nearly $100 \mathrm{~h}$.

The blade shapes before and after optimization are shown in Figure 7, where the 2D-opt blade is considered the initial blade for the optimization and the 3D-opt blade is the optimized blade. It is evident from the figure that compared to the initial blade, the chord length of the root of optimized blade increases and the chord length of the tip decreases. Table 5 shows a comparison between the aerodynamic performance of the three rotors. It can be seen from the table that the efficiency of the 2D-opt rotor (composed of 2D-opt blades) obtained after 2D optimization is significantly improved. The efficiency of the $3 \mathrm{D}$-opt rotor (composed of the 3D-opt blades) obtained after 3D optimization is further improved, reaching 0.910. During optimization, the stall margin is not used as the optimization objective, and the stall margin of optimized rotor is significantly smaller than that of the initial rotor (composed of the initial blades). The stall margin is expressed as follows:

$$
\mathrm{SM}=\left(\frac{\pi_{s}^{*}}{\pi_{o}^{*}} \times \frac{\dot{m}_{\mathrm{o}}}{\dot{m}_{s}}-1\right) \times 100 \%
$$

It can be seen from the characteristic curves in Figures $8(\mathrm{a})$ and $8(\mathrm{~b})$ that the $2 \mathrm{D}$-opt rotor and $3 \mathrm{D}$-opt rotor have no mass flow rate margin (i.e., the mass flow rate does not change with changes in operating conditions), and the stall point is very close to the design point. However, the original rotor has a mass flow rate margin. Therefore, the stall margins of the $2 \mathrm{D}$-opt rotor and $3 \mathrm{D}$-opt rotor are smaller than that of the original rotor, as shown in Table 5. For a supersonic rotor, the inlet relative Mach number is supersonic along its blade span and usually does not have a mass flow rate margin. In the following section on the method of improving the stall margin, it is explained why the original rotor has a mass flow rate margin. It can be seen from the characteristic curves of pressure ratio vs. efficiency 


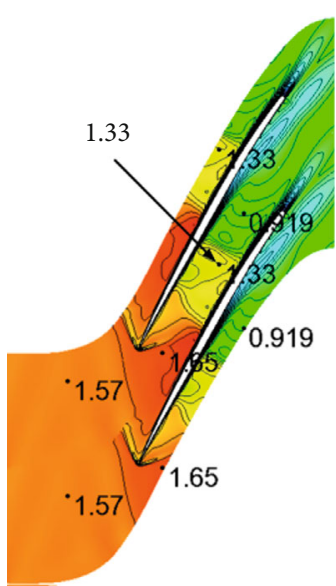

(a) 3D-opt rotor

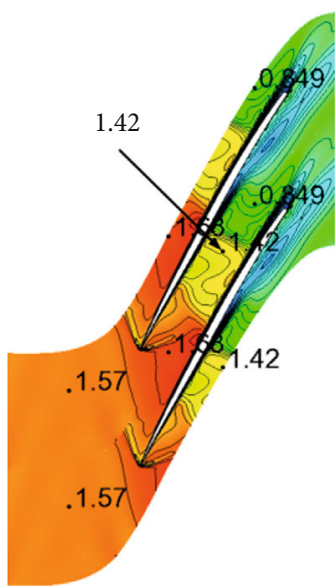

(c) Shroud $+2 \mathrm{~mm}$

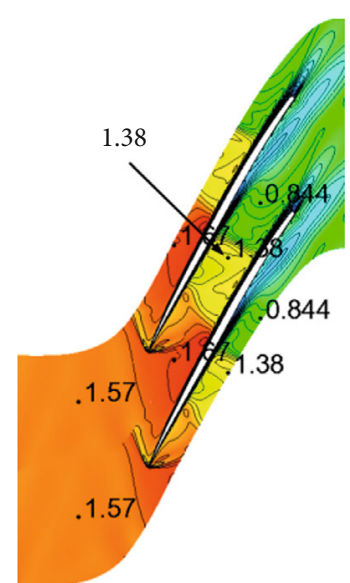

(b) Shroud $+1 \mathrm{~mm}$

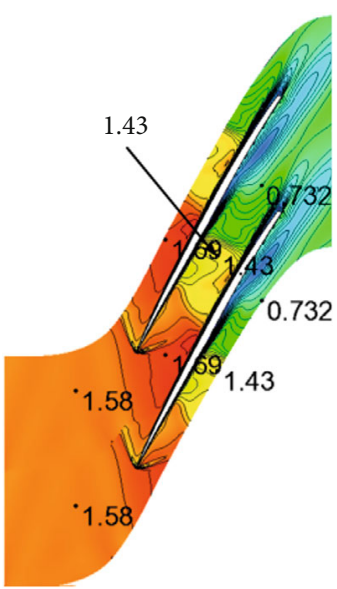

(d) Shroud $+3 \mathrm{~mm}$

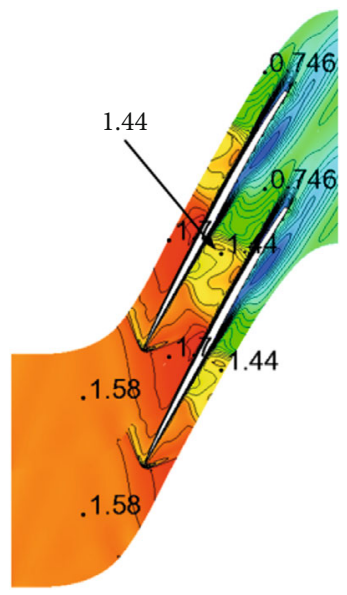

(e) Shroud $+4 \mathrm{~mm}$

Figure 15: Mach number contours of $90 \%$ span at the design point.

(Figure 8(c)) that the efficiency of the 3D-opt rotor is larger than that of $2 \mathrm{D}$-opt rotor, while the efficiency of the 2D-opt rotor is larger than that of original rotor in the entire working range.

Figure 9 shows the radial distribution of average outlet tangential parameters at the design point. In Figure 9(a), the distribution of total pressure ratio of the $2 \mathrm{D}$-opt rotor and 3D-opt rotor are more uniform along the span, which is consistent with the design goal. Figure $9(\mathrm{~b})$ shows that compared to the original rotor, the efficiency of the $2 \mathrm{D}$ opt rotor is significantly improved at the blade span above $70 \%$. Further, compared to the $2 \mathrm{D}$-opt rotor, the efficiency of the 3D-opt rotor is improved in the entire span range. 


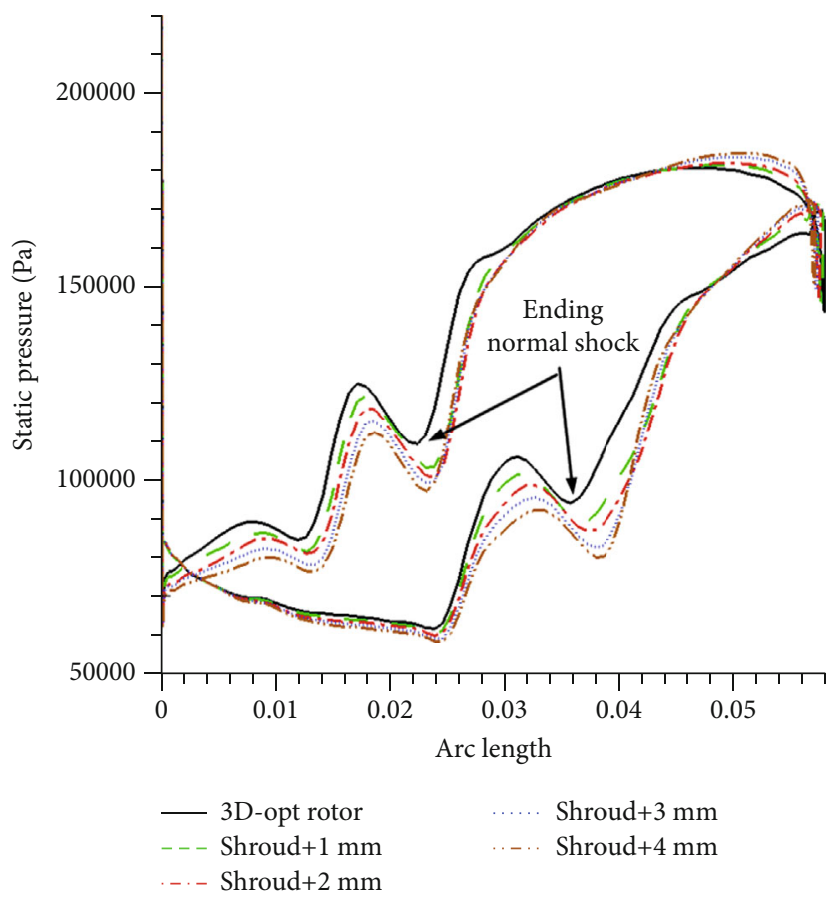

(a) Design point

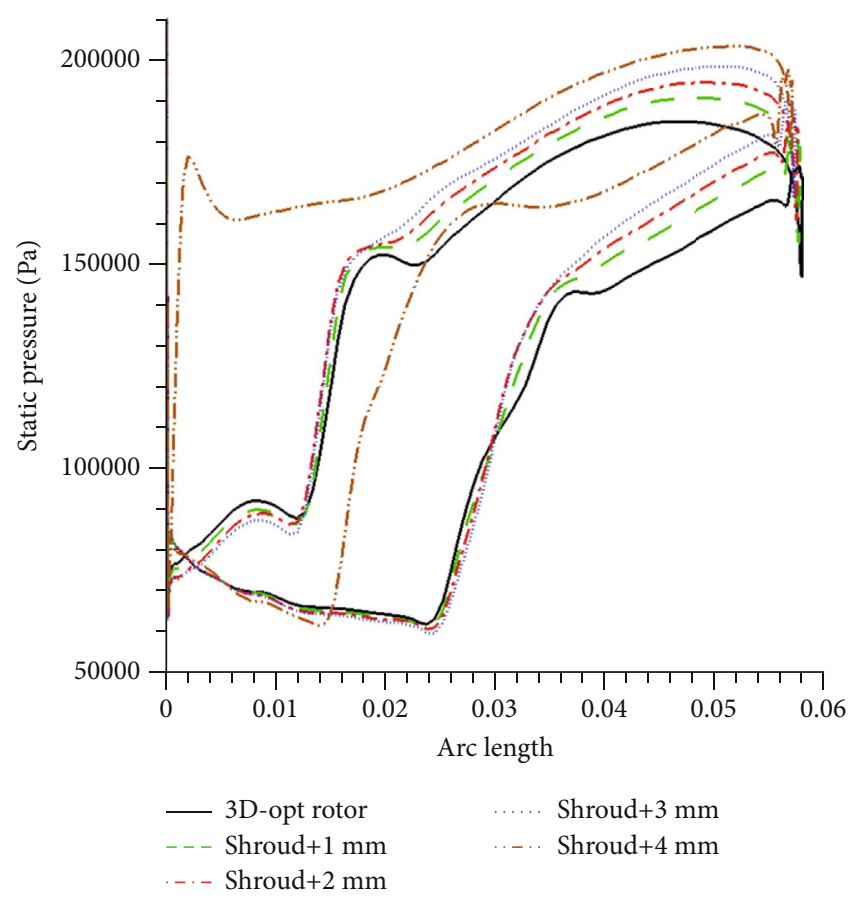

(b) Near-stall point

Figure 16: Distribution of surface static pressure at $90 \%$ span.

Figure 10 shows the Mach number contours of the three rotors at $10 \%, 50 \%, 90 \%$, and $99 \%$ spans. It is evident that the shock structures of the three rotors at $10 \%, 50 \%$, and $90 \%$ spans are exactly the same. The intensity of the final normal shock at $10 \%, 50 \%$, and $90 \%$ spans decreases according to the original rotor, 2D-opt rotor, and 3D-opt rotor ((Figures 10(a)-10(c)). Therefore, the low-velocity area near the pressure surfaces downstream of the ending normal shock also decreases ((Figure 10(c)). The low-velocity area near the annular wall (at 99\% blade span) also decreases accordingly (Figure 10(d)).

\section{Improving the Stall Margin of Supersonic Rotor}

The rotor stall margin is not taken into account in the $2 \mathrm{D}$ and 3D optimizations, so the efficiency of the supersonic rotor at the design point obtained by the optimizations is high, but the stall margin is very small. To improve the stall margin of the rotor, the flow characteristics of the supersonic rotor near the stall point were analyzed. Then, the stall margin was improved by modifying the blade tip sweep, meridian flow path, and blade tip chord length without affecting the performance of the design point as much as possible.

4.1. Flow Characteristics of 3D-Opt Rotor near the Stall Point. Figure 11 shows the Mach number contours of the 3D-opt rotor at the stall point. It is clear that the ending normal shock is in the middle of the channel span, rather than at the blade passage entrance. If the outlet pressure of the rotor slightly increases such as $10 \mathrm{~Pa}$, then the calculation of the flow field diverges. The development process of the flow field stall is shown in Figure 12. With the increase in the number of iterative calculation steps, the ending normal shock moves upstream and merges with the upstream passage shock, and it becomes close to the rotor entrance when the iterative calculation reaches 4600 steps. At 5000 steps, the merging shock at the blade tip is pushed out of the passage, and the flow is in a state of large separation, which blocks the flow passage, and the rotor is stalled. However, the shock in the middle span is not yet detached, and the flow field in the root is normal. Therefore, the stall of the supersonic rotor is caused by the detachment of the tip shock under high outlet pressure, which is also the reason for stall in most supersonic and transonic rotors. The following subsection focuses on the stall at the tip of the blade to improve the stall margin.

4.2. Increasing the Exit Radius of Upper Meridian. The inlet relative Mach number of the supersonic rotor is supersonic, and the outlet relative Mach number is subsonic. The flow in the blade passage at the tip of the rotor is similar to the flow in a converging and expanding supersonic nozzle (Laval nozzle). A normal shock is generated in the expansion section downstream of the throat to transform the supersonic flow into a subsonic flow. This normal shock is equivalent to the ending normal shock in the blade passage. The farther the normal shock is from the throat, the stronger the ability to withstand outlet pressure and the harder it is to withdraw from the inlet. The ability to withstand the outlet pressure of the Laval nozzle is closely related to the nozzle's shape. Therefore, by varying the shape of the upper meridian, the local shape of the converging and expanding flow passage 


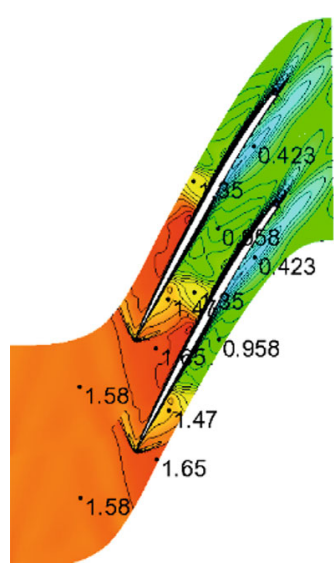

(a) 3D-opt rotor

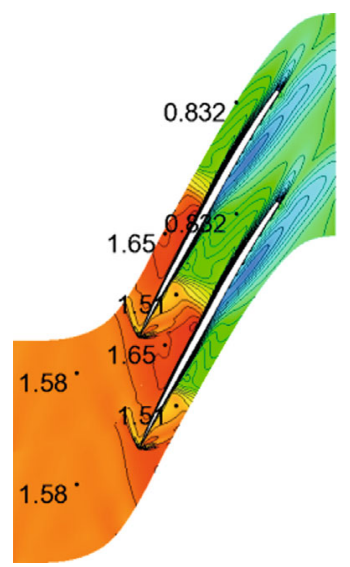

(c) Shroud $+2 \mathrm{~mm}$

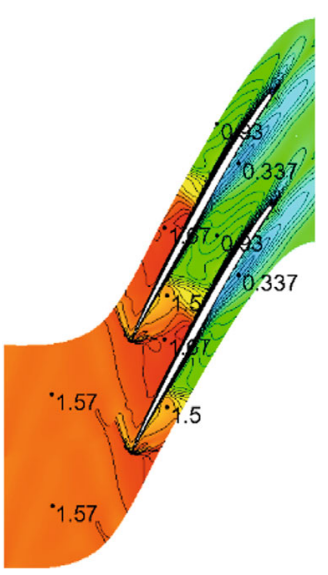

(b) Shroud $+1 \mathrm{~mm}$

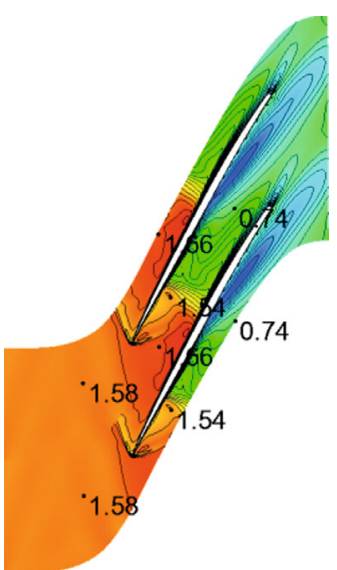

(d) Shroud $+3 \mathrm{~mm}$

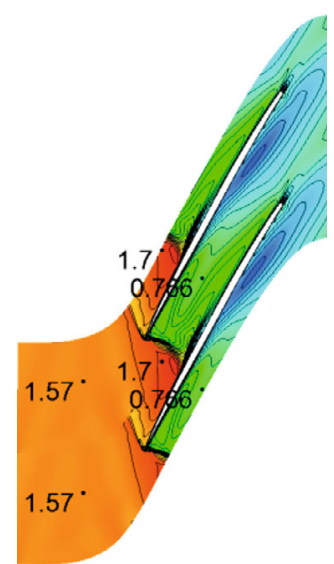

(e) Shroud $+4 \mathrm{~mm}$

FIGURE 17: Mach number contours of $90 \%$ span at the near-stall point.

near the blade tip can be modified to improve the stall margin.

Figure 13 shows that the radius of the original upper meridian gradually decreases along the flow direction in the middle segment (blade passage between the leading and trailing edges), and the front and rear segments are straight horizontal lines. The radius of the upper meridian at the trailing edge of the blade is increased by $1,2,3$, and $4 \mathrm{~mm}$ corre- sponding to the casing outlet radius of $111,112,113$, and $114 \mathrm{~mm}$, respectively. The radius of the front section remains unchanged, while the radius of the middle segment varies almost linearly, forming 4 new meridians, and the corresponding rotors are called Shroud $+1 \mathrm{~mm}$, Shroud $+2 \mathrm{~mm}$, Shroud $+3 \mathrm{~mm}$, and Shroud $+4 \mathrm{~mm}$.

Table 6 lists the aerodynamic performances of five rotors: the $3 \mathrm{D}$-opt rotor, Shroud $+1 \mathrm{~mm}$ rotor, Shroud $+2 \mathrm{~mm}$ rotor, 


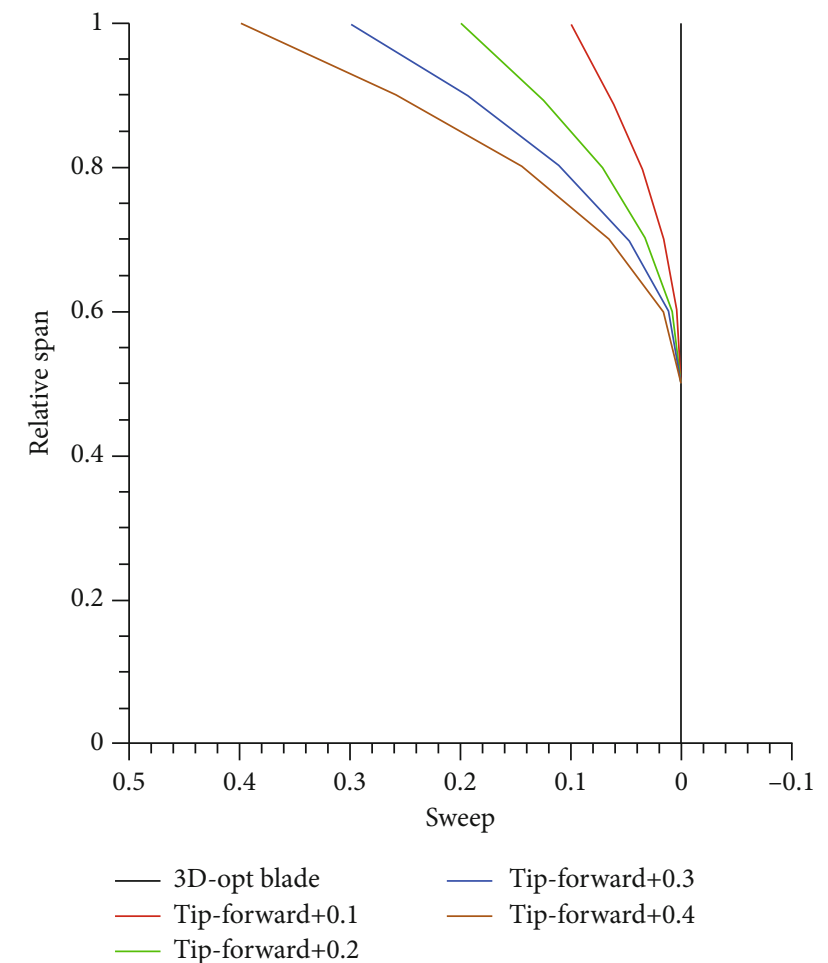

FIGURE 18: Stacking lines of rotor blades.

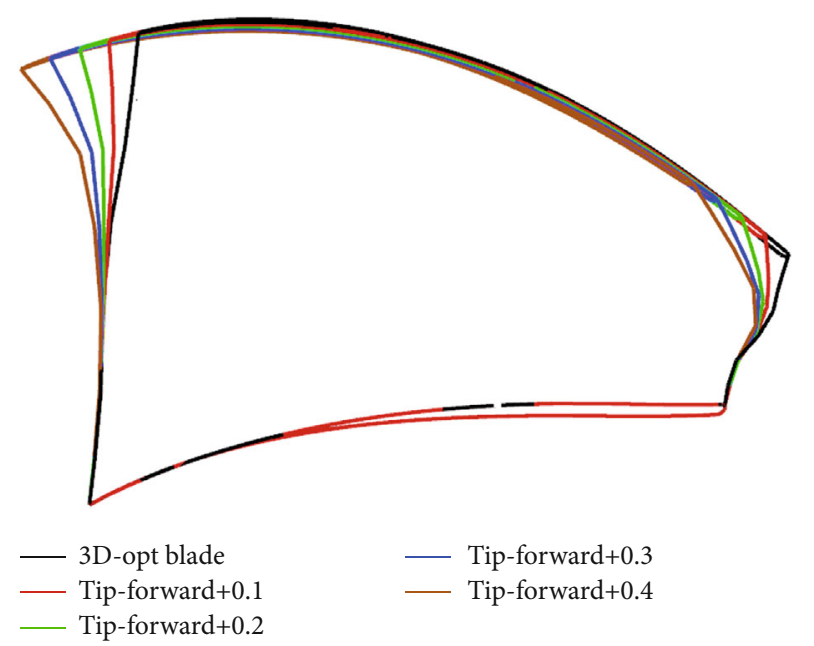

Figure 19: Shapes of rotor blades.

TABLE 7: Performance of five rotors with different forward sweeps of the blade tip.

\begin{tabular}{lcccc}
\hline & $\dot{\mathrm{m}}_{d}(\mathrm{~kg} / \mathrm{s})$ & $\pi_{k, d}^{*}$ & $\eta_{k, d}^{*}$ & $\mathrm{SM}(\%)$ \\
\hline 3D-opt rotor & 6.37 & 2.80 & 0.910 & 1.59 \\
Tip-forward+0.1 & 6.37 & 2.80 & 0.905 & 2.34 \\
Tip-forward+0.2 & 6.38 & 2.80 & 0.903 & 2.72 \\
Tip-forward+0.3 & 6.38 & 2.80 & 0.900 & 12.52 \\
Tip-forward+0.4 & 6.39 & 2.80 & 0.898 & 13.86 \\
\hline
\end{tabular}

Shroud $+3 \mathrm{~mm}$ rotor, and Shroud $+4 \mathrm{~mm}$ rotors. It is clear that the variation in upper meridian has a negligible influence on the mass flow rate at the design point, and it remains unchanged within the range of total pressure ratio for stable operation. Figure 14 shows the relationship between total pressure ratio and efficiency. It can be seen from Figure 14 and Table 6 that with the expansion of upper meridian, the rotor efficiency decreases, while the maximum total pressure ratio and the stall margin increase.

Since the change in upper meridian only affects the flow field near the tip, the Mach number contours of $90 \%$ span at the design point are obtained, as shown in Figure 15. It is clear that with the expansion of upper meridian, the Mach number in front of the ending normal shock increases, and the shock intensity increases, which induces an increase in the low-velocity area downstream of the shock, leading to a decrease in the efficiency.

Figure 16 shows the pressure distribution of $90 \%$ span on the blade surfaces at the design point and near the stall point. It can be seen from Figure 16(a) that as the upper meridian expands and the ending normal shock shifts downstream at the design point. According to Figure 16(b), near the stall point, with the expansion of the upper meridian, the static pressure at the end of the suction surface and the pressure surface increases, and the ability to withstand outlet pressure increases. As the upper meridian expands, the stall margin is increased due to the movement of ending normal shock downstream at the design point and the improvement of resistance to the outlet pressure near the stall point, as shown in Table 6.

For the converging and expanding flow passage of supersonic inlet flow and subsonic outlet flow, a normal shock wave is generated in the expansion section, and as the outlet pressure increases, the shock moves upstream. When the normal shock reaches the aerodynamic throat, the outlet pressure is further increased and the shock moves from the throat to the upstream of the passage entrance to form a detachment shock and cannot stay in the convergent section. Corresponding to the flow at the tip of the supersonic rotor passage, near the stall point, the position of the ending normal shock is that of the throat. Figure 17 shows the Mach number contours of the five rotors at $90 \%$ span of the nearstall point. It is evident that the throats of $3 \mathrm{D}$-opt rotor and Shroud $+1 \mathrm{~mm}$, Shroud $+2 \mathrm{~mm}$, and Shroud $+3 \mathrm{~mm}$ rotors are located in the blade passages. For the Shroud $+4 \mathrm{~mm}$ rotor, due to the increase in the throat area, the ending normal shock and the upstream channel shock merges into a normal shock, which stabilizes at the passage entrance. Consequently, the Mach number in front of the shock reaches 1.7, and the flow capacity of the throat can still meet the upstream flow rate requirements. Therefore, the stall margin of Shroud $+4 \mathrm{~mm}$ rotor is maximum (Table 6), while the decrease in efficiency is also the largest, as shown in Table 6 and Figure 14.

4.3. Forward Sweep of Blade Tip. Hah et al. [17] suggested that the geometric characteristics of forward swept blade tip caused the ending normal shock in the flow passage near the blade tip to move downstream, which ensured an increase 


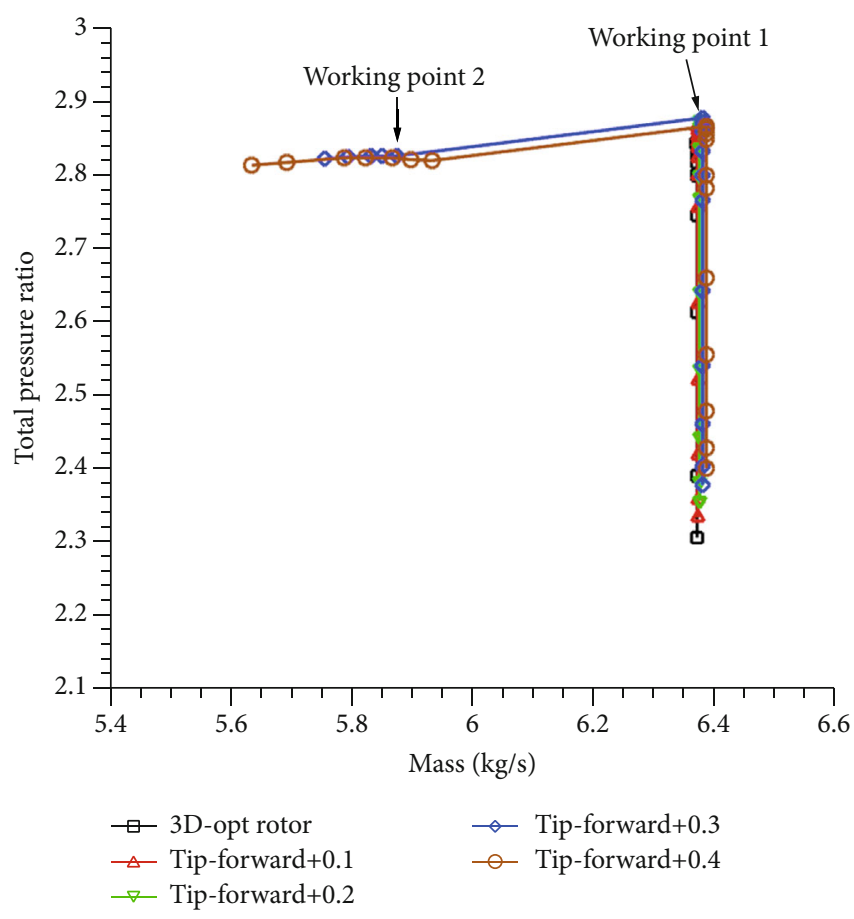

(a)

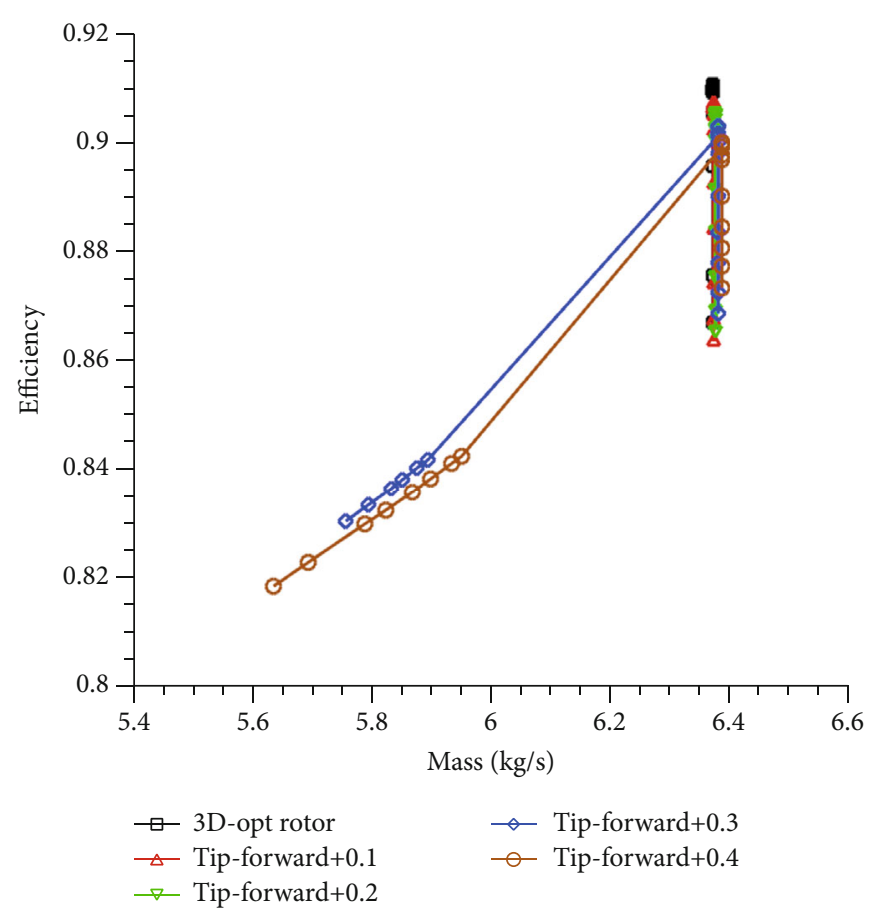

(b)

FIGURE 20: Performance curves of the five rotors with different forward sweeps of blade tip.

in the stall margin. Denton and $\mathrm{Xu}[18,19]$ showed that the forward sweep of the blade tip reduced the load on the front part of the blade, weakened the shock intensity, and improved the stability margin. McNulty et al. [20] found that forward sweep caused a redistribution of radial flow in a forward swept rotor, i.e., spanwise redistribution of flow toward the blade tip. Xingmin et al. [21, 22] investigated the influence of the blade tip sweep on the inlet flow in a transonic rotor and found that the forward sweep of tip increased the axial velocity and decreased the circumferential velocity. Earlier studies on the forward sweep of blade tip mainly focused on the subsonic and transonic compressor rotors. However, the inlet relative Mach number of a supersonic rotor is supersonic along the blade span, and the influence of the blade tip sweep on its flow stall characteristics needs to be analyzed to determine their similarities and differences.

Here, the influence of the forward sweep of tip is examined for the supersonic 3D-opt rotor. The stacking line sweep is defined as the chord sweep, and the sweep amount is the relative value of blade height. The amount of forward sweep at the blade tip is $0.1,0.2,0.3$, and 0.4 . The end point of the forward sweep is at $50 \%$ span, and the variation in sweep amount along the blade height is distributed in a quadratic manner. Further, the derivative of sweep amount with respect to the blade height at $50 \%$ span is 0 . Figure 18 shows the above stacking lines of the four forward swept blades (tipforward +0.1 , tip-forward+0.2, tip-forward +0.3 , and tip-forward+0.4) and the nonswept blade (3D-opt blade). Figure 19 shows the 3D shapes of the corresponding blades.

Table 7 shows that as the forward sweep of tip increases, the stall margin of rotor increases and the efficiency decreases slightly. When the forward sweep amount of tip increases to more than 0.3 (tip-forward +0.3 , tip-forward +0.4 ), the stall margin increases sharply. It can be seen from Figure 20 that the abrupt increase in the stall margin is due to a significant decrease in the mass flow rate near the stall point, i.e., the two supersonic rotors have mass flow rate margins. In addition, for the tip-forward +0.3 and tip-forward +0.4 rotors, the mass flow rate remains unchanged during the initial stage of increase in the outlet pressure. However, after the outlet pressure reaches a certain value, the mass flow rate decreases suddenly with the increase in the outlet pressure, and the total pressure ratio and efficiency decreases accordingly (from the working point 1 to 2 in Figure 20), and the flow field cannot stabilize between working points 1 and 2 .

Firstly, the influence of the forward sweep of the blade tip on the position of ending normal shock and the stall margin is analyzed. Figure 21 shows that as the forward sweep of the tip increases, the position of the ending normal shock at $90 \%$ span shifts downstream (as shown in Figure 21(c)), but the positions at $10 \%$ and $50 \%$ spans are not affected (as shown in Figures 21(a) and 21(b)). Figure 22 shows the static pressure contours on the pressure surfaces of five rotor blades at the design point. It is evident that the absolute position of the ending normal shocks remain unchanged with the variation in the forward sweep of tip, i.e., the relative position to the blade root remain unchanged, and the ending normal shock is perpendicular to the upper and lower endwalls. Specifically, the forward sweep of tip has a minor effect on its spatial position [23]. Therefore, as the forward sweep amount of the tip increases, if the ending normal shock is far away from the aerodynamic throat, the ability of the tip flow to 


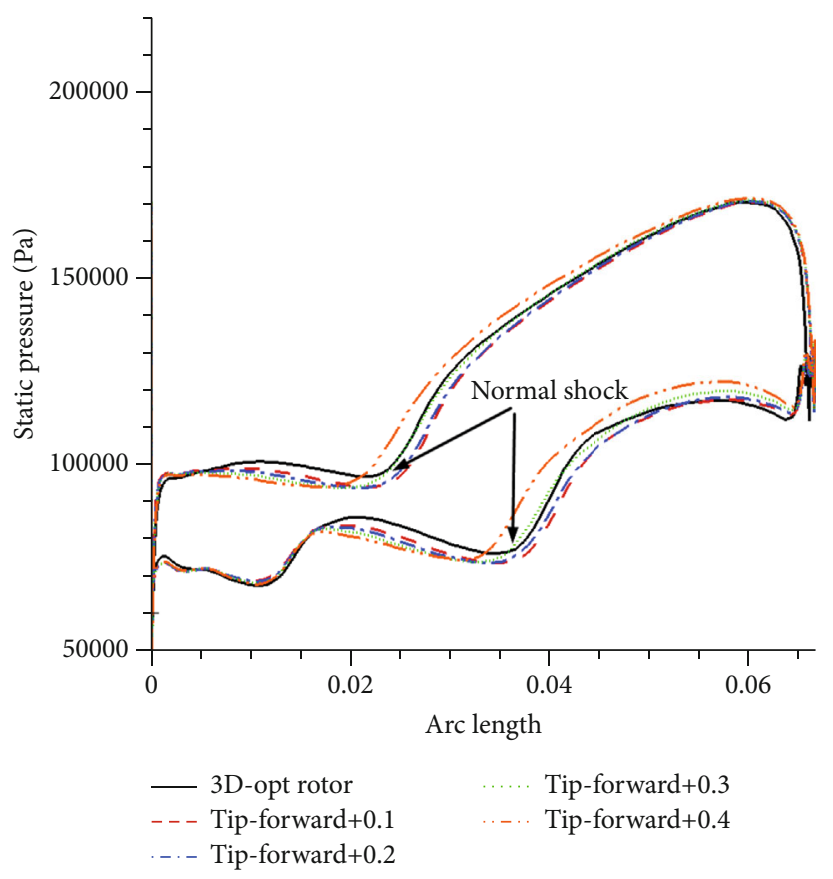

(a) $10 \%$ span

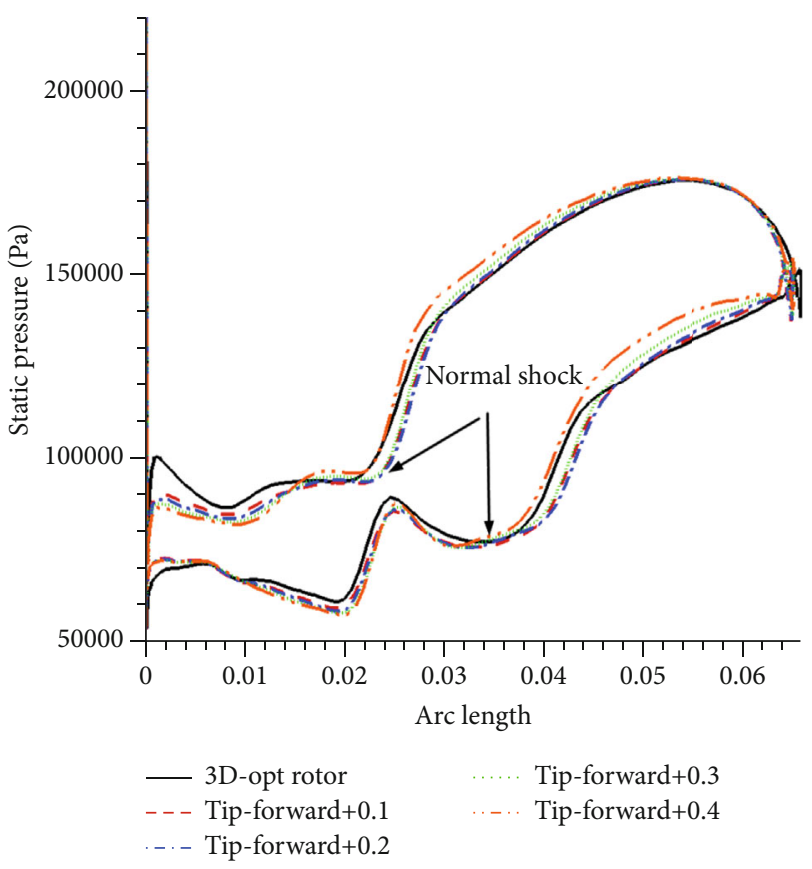

(b) $50 \%$ span

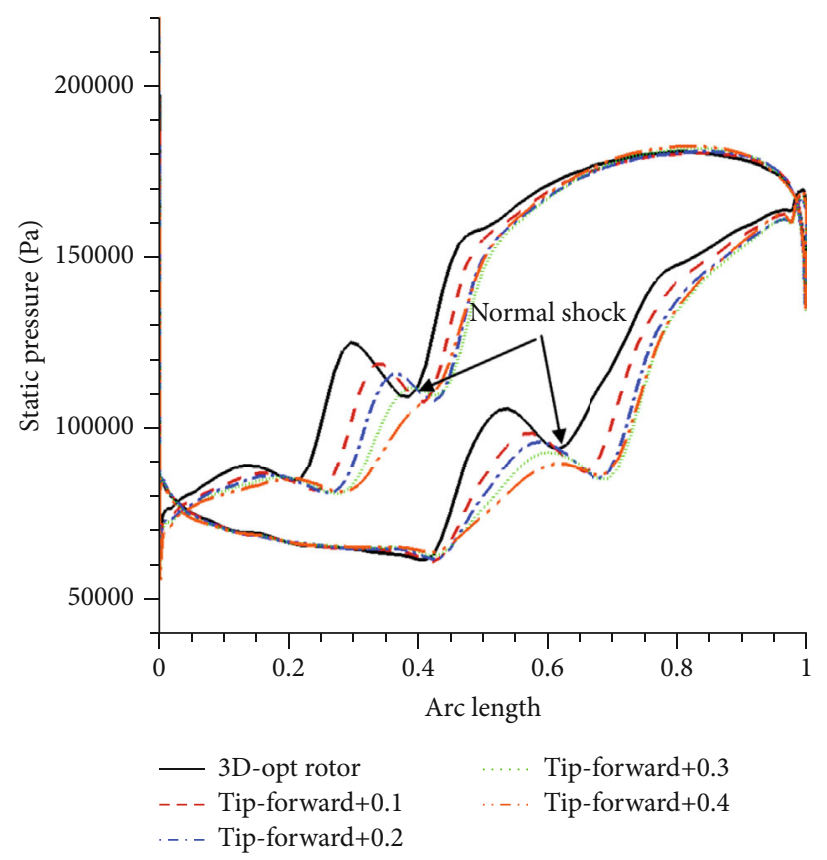

(c) $90 \%$ span

FIgURE 21: Static pressure distribution on the surface of five blades at the design point.

withstand outlet pressure increases, so the stall margin of the rotor increases, which is the main reason for the increase in the sweep stall margin of tip. There is an expansion passage from the throat to the ending normal shock, which leads to an increase of the Mach number. The smaller the gap between the ending normal shock and the trailing edge, the higher the Mach number in front of the shock, the stronger the shock intensity (as shown in Figure 23), and the lower the efficiency (the impact on efficiency is small, as shown in Table 7).

Secondly, the mechanism responsible for the effect of forward sweep of the tip on the flow margin and the reason why the working point cannot be stabilized between the points 1 and 2 are analyzed. Figure 24 shows the Mach number contours of $90 \%$ span at the working point 1 in Figure 19. Here, the position of ending normal shock represents the position 


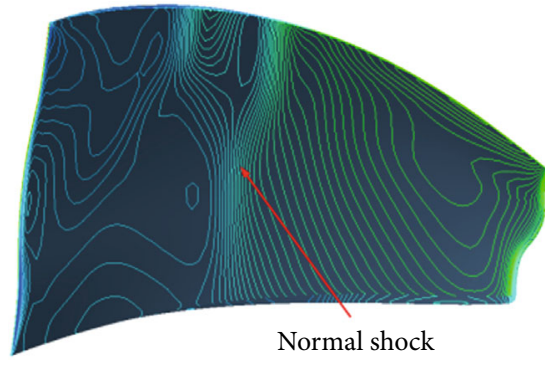

(a) 3D-opt rotor

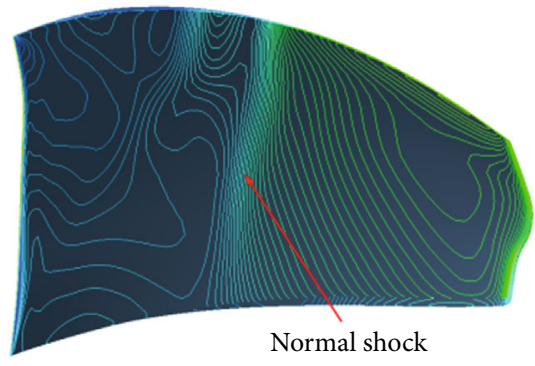

(c) Tip-forward +0.2

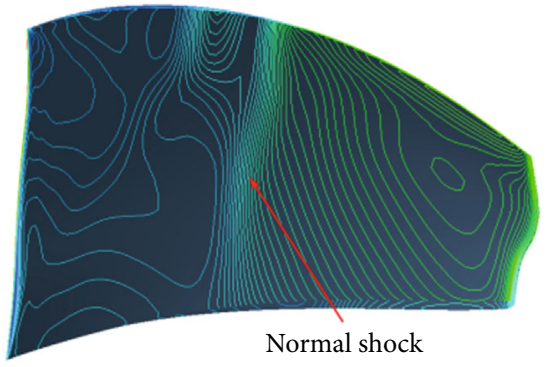

(b) Tip-forward +0.1

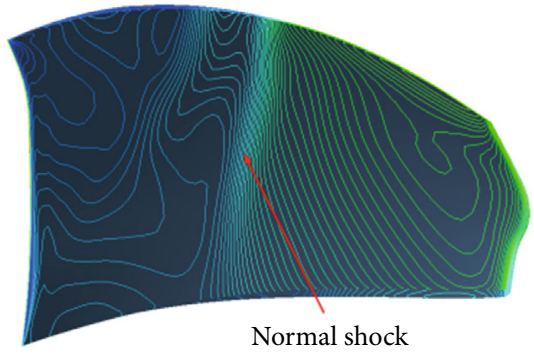

(d) Tip-forward +0.3

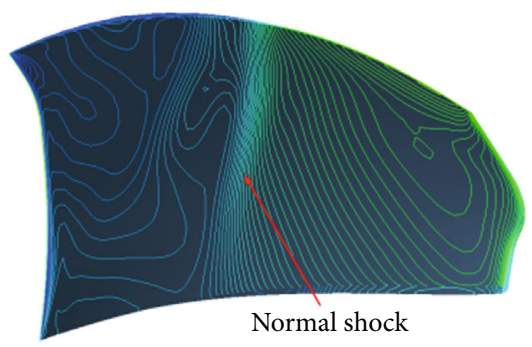

(e) Tip-forward +0.4

FIGURE 22: Static pressure distributions on the pressure surface of five blades at the design point.

of the aerodynamic throat on the blade tip region. If the outlet pressure is continuously increased, the ending normal shock advances from the throat upstream to the passage entrance. Figure 25 shows that for the tip-forward +0.3 and tip-forward +0.4 rotors, near the stall point, the ending normal shocks merge with the upstream passage shock and are pushed out of the passage, and they can be stabilized at the passage entrance (Figure 25(c)). For the 3D-opt, tip-forward +0.1 , and tip-forward +0.2 rotors, the ending normal shocks are located at the aerodynamic throats. If the outlet pressure is increased further, they exit the passages and the rotors stall. Notably, for the two rotors with larger forward sweep (tip-forward+0.3, tip-forward+0.4), restricted by these stable tip shocks at the passage entrance, the detachment shocks in the middle span stabilizes in front of the passage entrance, which results in an overflow. The mass flow rate is reduced at the stall point, which causes the supersonic rotors to exhibit mass flow rate margin. Consequently, the stall margins of tip-forward +0.3 and tip-forward +0.4 rotors are much larger than that of $3 \mathrm{D}$-opt, tip-forward+0.1, and tip-forward +0.2 rotors.

4.4. Increasing the Chord Length of Blade Tip. When the number of blades is certain, the greater the blade solidity, the longer the chord length of blade, and the longer the effective flow passage of the cascade. The length of the flow passage is crucial to shock organization, which reduces the shock wave loss and increases the stall margin. However, the longer the blade chord, the greater the proportion of the surface layers on the blade surfaces, which may adversely affect the efficiency and stall margin. Therefore, the blade solidity has an optimal value.

Because the tip-forward +0.3 rotor has better overall performance, it is selected to study the influence of the chord length of the blade tip on the stall margin. Starting from $60 \%$ span, the chord length of tip was increased by 0.05 , $0.10,0.15$, and 0.20 times. The blade shapes are shown in Figure 26.

Table 8 shows that when the chord length of blade tip increases by 0.10 times, the stall margin reaches $18.11 \%$. If the chord length is further increased, the stall margin begins to decrease. Further, it is clear from Table 8 that as the chord length of the blade tip increases, the mass flow rate at the stall point $\left(\dot{m}_{\mathrm{s}}\right)$ initially decreases and then increases, which causes the stall margin of the rotor to increase first and then decrease. It can be seen in Figure 27 that for different chord lengths of the blade tip, the Mach number in front of the shocks remains basically the same, and the rotor efficiency 


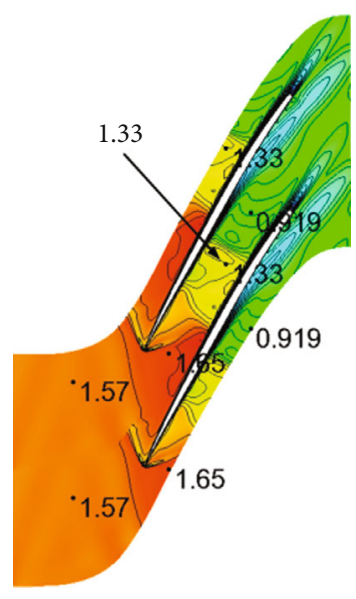

(a) 3D-opt rotor

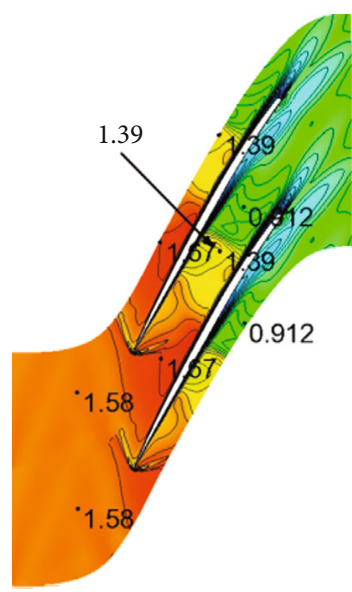

(c) Tip-forward +0.2

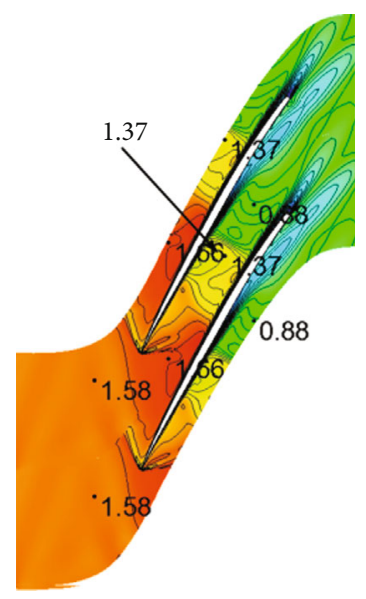

(b) Tip-forward +0.1

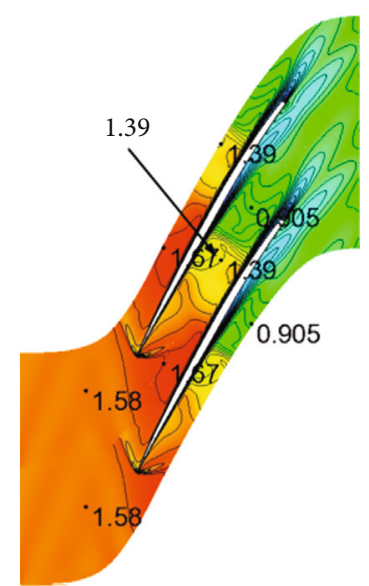

(d) Tip-forward +0.3

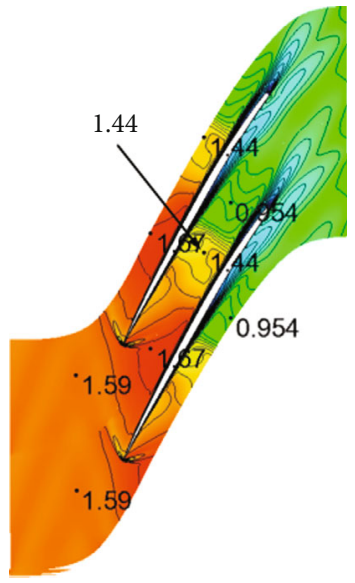

(e) Tip-forward +0.4

Figure 23: Mach number contours at $90 \%$ span of the five rotors at the design point. 


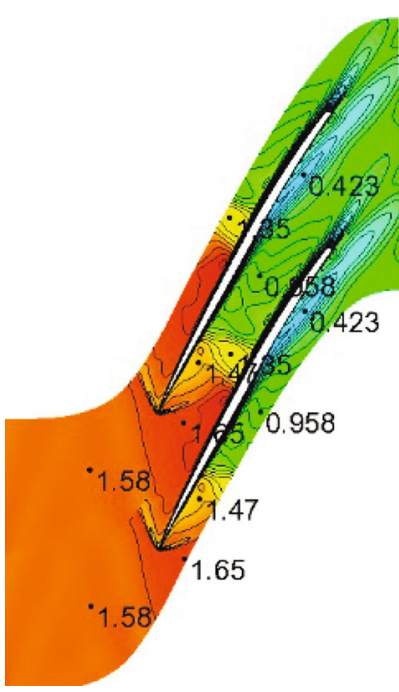

(a) 3D-opt rotor

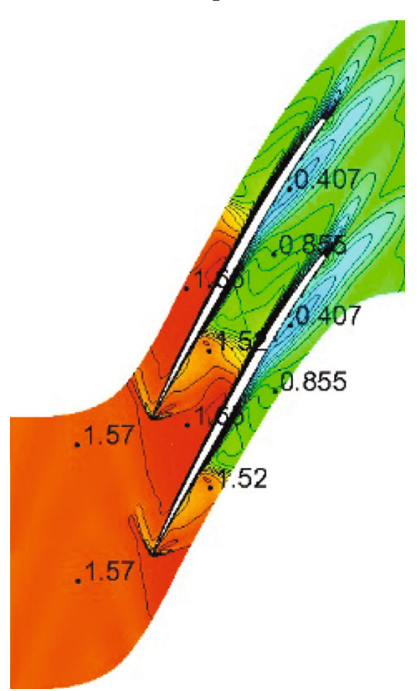

(c) Tip-forward +0.2

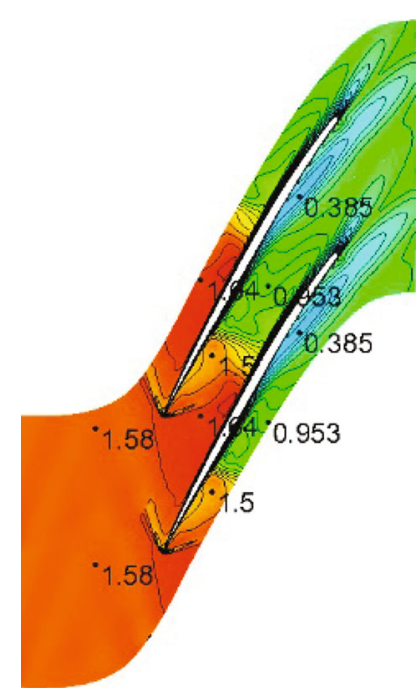

(b) Tip-forward+0.1

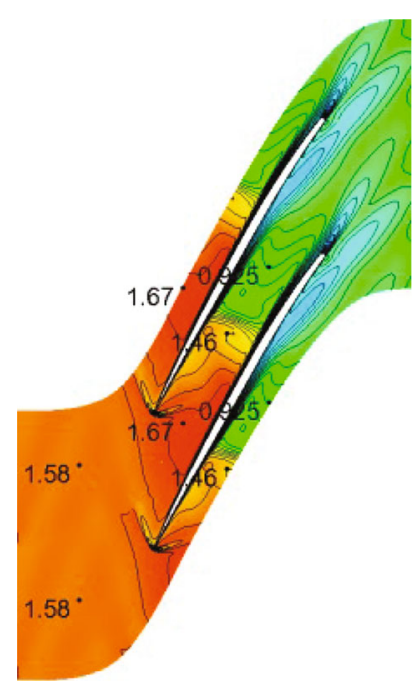

(d) Tip-forward +0.30

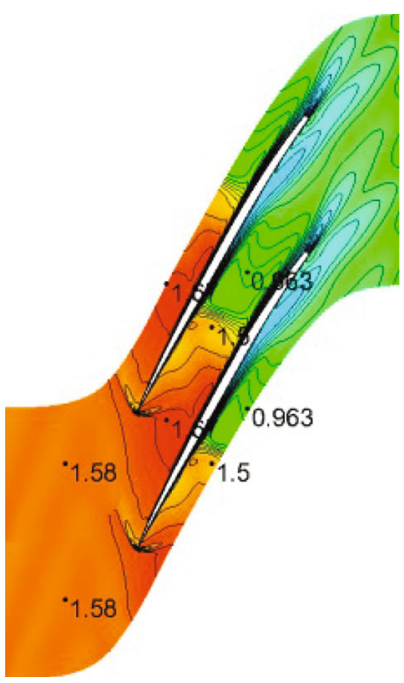

(e) Tip-forward +0.40

FIGURE 24: Mach number contours at $90 \%$ span of the five rotors at working point 1. 


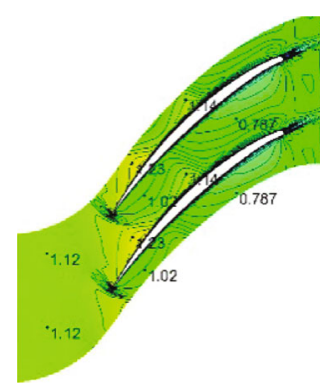

$3 \mathrm{D}$-opt rotor

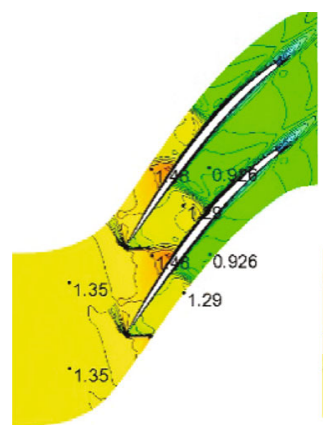

3D-opt rotor

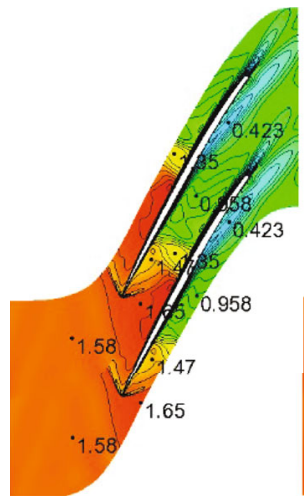

3D-opt rotor

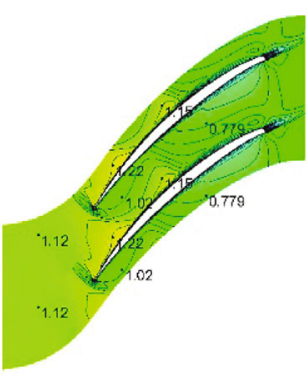

Tip-forward +0.1

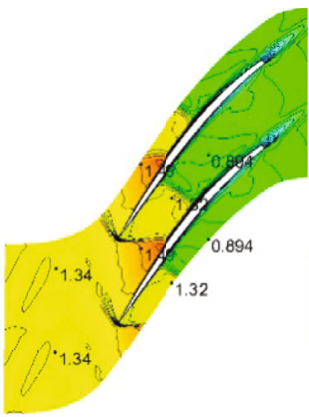

Tip-forward +0.1

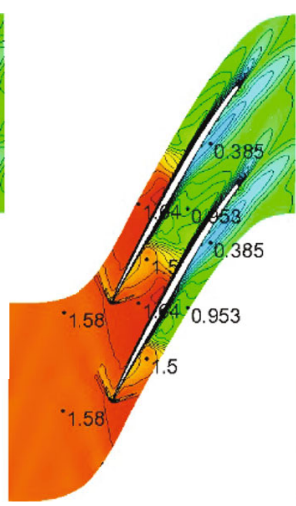

Tip-forward +0.1

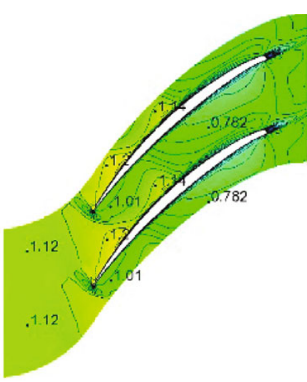

Tip-forward +0.2

(a) $10 \%$ span

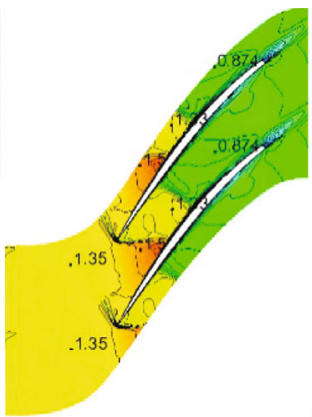

Tip-forward +0.2

(b) $50 \%$ span

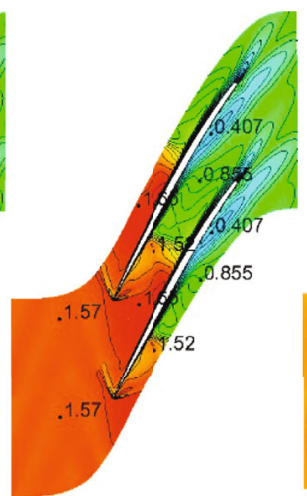

Tip-forward +0.2

(c) $90 \%$ span

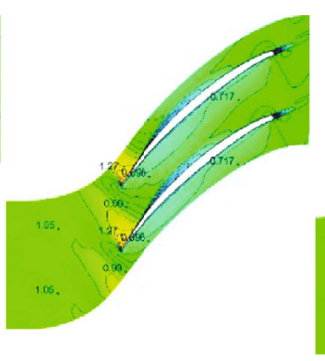

Tip-forward +0.30

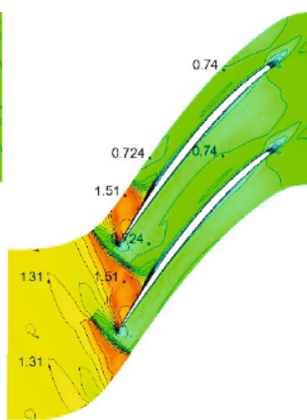

Tip-forward +0.3

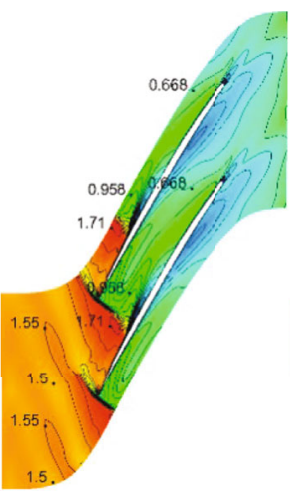

Tip-forward +0.3

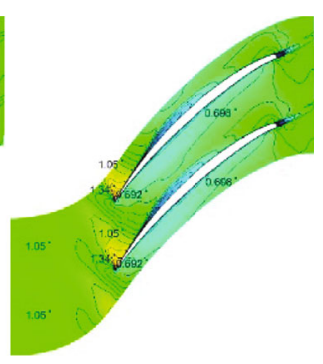

Tip-forward +0.4

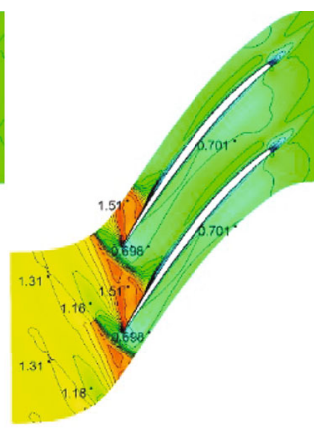

Tip-forward +0.4

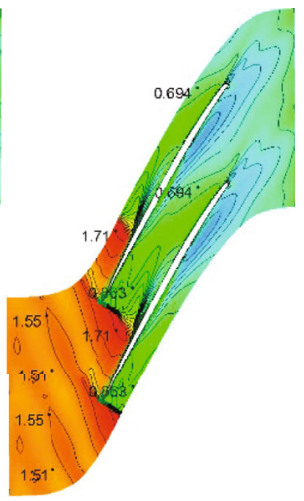

Tip-forward +0.4

FiguRE 25: Mach number contours near the stall point.
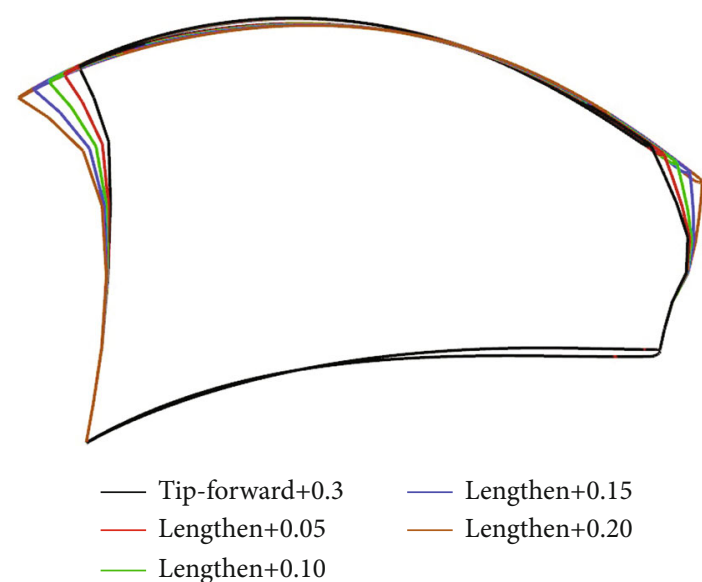

Figure 26: Shapes of the five blades.
TABLE 8: Aerodynamic performance of five rotors with different tip chord lengths.

\begin{tabular}{lccccc}
\hline & $\dot{m}_{d}(\mathrm{~kg} / \mathrm{s})$ & $\dot{m}_{s}(\mathrm{~kg} / \mathrm{s})$ & $\pi_{k, d}^{*}$ & $\eta_{k, d}^{*}$ & $\mathrm{SM}(\%)$ \\
\hline Tip-forward +0.30 & 6.38 & 5.70 & 2.80 & 0.900 & 12.52 \\
Lengthen+0.05 & 6.38 & 5.57 & 2.80 & 0.901 & 15.51 \\
Lengthen +0.10 & 6.38 & 5.40 & 2.80 & 0.902 & 18.11 \\
Lengthen+0.15 & 6.38 & 5.45 & 2.80 & 0.903 & 17.59 \\
Lengthen+0.20 & 6.39 & 5.48 & 2.80 & 0.904 & 17.24 \\
\hline
\end{tabular}

is essentially unchanged (as shown in Table 8). Figure 28(a) shows the distributions of blade surface pressures at $90 \%$ span in the direction of the absolute chord length. It is clear that as the chord length of the blade tip increases, the ending normal shock at $90 \%$ span becomes farther away from the 


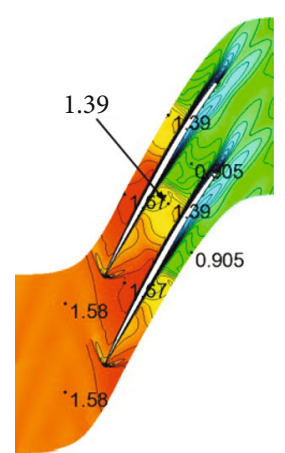

(a) Tip-forward +0.30

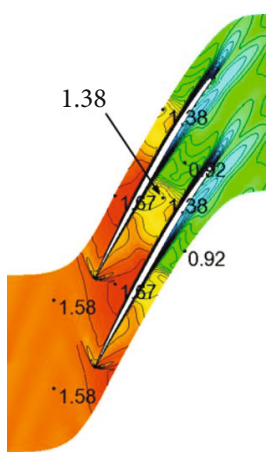

(b) Lengthen +0.05

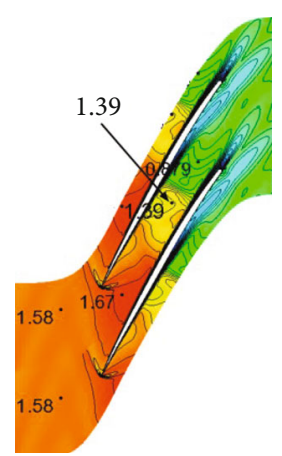

(c) Lengthen +0.10

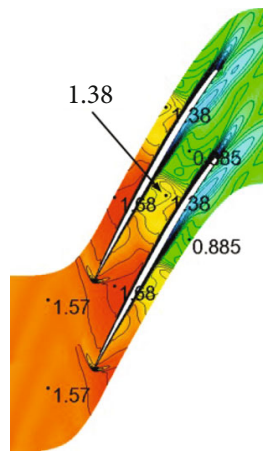

(d) Lengthen +0.15

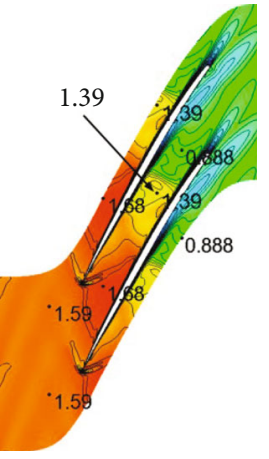

(e) Lengthen +0.20

Figure 27: Mach number contours for $90 \%$ span at the design point.

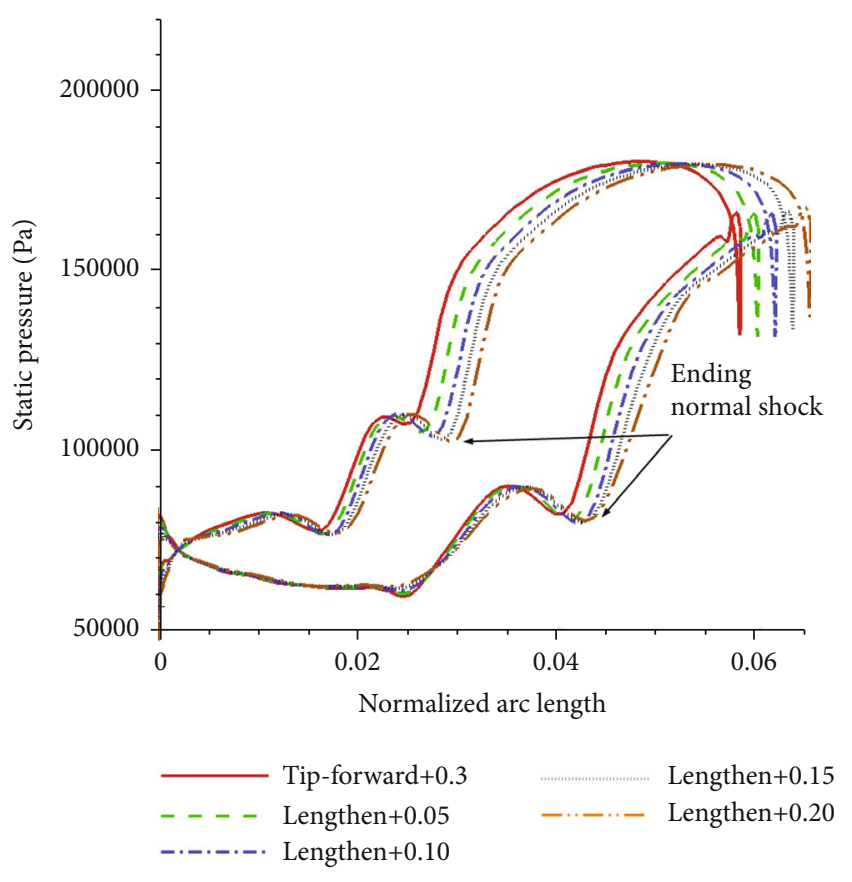

(a) $90 \%$ span (absolute chord length)

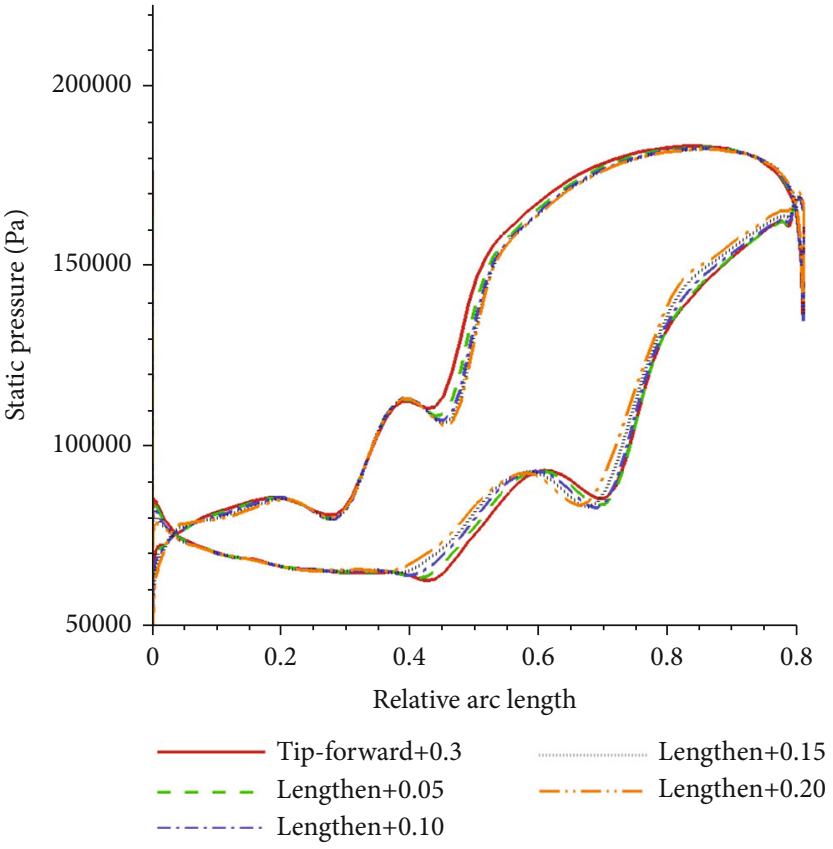

(b) $90 \%$ span (relative chord length)

FIGURE 28: Static pressure distributions on the blade surface for $90 \%$ span at the design point.

leading edge, which causes an increase in the stall margin. In Figure 28(b), for different chord lengths of the blade tip, the blade surface pressure at $90 \%$ span remains basically unchanged in the direction of relative chord length, indicating that increasing the chord length of the blade tip can retain a constant flow field structure in the tip region (Figure 27), so the rotor efficiency is nearly unchanged (Table 8). 


\section{Conclusion}

One of the main reasons for these advances is the continuous increase in the rotational speed, which can cause the inlet relative flow to develop into fully supersonic flow, and the corresponding compressor is called supersonic compressor. In this study, an aerodynamic design method based on the combination of automatic optimization and manual design was proposed to design supersonic compressor rotors with a high total pressure ratio. This automatic optimization method was used to achieve high efficiency at the design point, and the forward sweep of the blade tip, chord length of the blade tip, and meridian flow path were modified to improve the stall margin. A supersonic rotor with total pressure ratio 2.8 was designed using the above method, which exhibited an efficiency of 0.902 at the design point and a stall margin of $18.11 \%$. The main results of the study are summarized as follows:

(1) According to the inlet flow characteristics of supersonic cascades, the initial supersonic blade profile was designed to reach the desired inlet Mach number and flow angle. Furthermore, 2D profile optimization and $3 \mathrm{D}$ blade optimization were utilized to greatly improve the efficiency at design points under the premise of reaching the desired mass flow rate and total pressure ratio. However, the stall margin was very low because the performance at the nondesign point was not considered in the optimization design process of rotor

(2) According to the analysis of flow near the stall point of the supersonic compressor rotor, the mechanism of rotor tip stall was established, and the two causes for the tip stall were elucidated. Firstly, in the tip area, the endwall boundary layer changed the position of the tip throat, causing the flow passage near the blade tip to converge first and then expand, and the aerodynamic throat appeared inside the flow passage, reducing the ability of the blade tip to withstand back pressure. Secondly, the low-speed areas caused by the tip-leakage-vortex breakage and boundary layer separation reduced the flow capacity of the blade tip, causing instability of the tip flow, which enhanced the stall of the rotor

(3) Through forward sweep of blade tip and expansion of upper meridian, the flow area of the throat could be increased, which improved the flow capacity. As the outlet pressure increased, the ending normal shock moved upstream and merged with the passage shock, and it stabilized at the entrance of the blade channel, which increased the stall margin. Restricted by these stable tip shocks at the passage entrance, the detachment shocks in the middle span stabilized in front of the passage entrance, which resulted in an overflow and reduced the mass flow rate at the stall point. This caused the supersonic rotor to generate mass flow rate margin, which further increased its stall margin
(4) The variation in the chord length of the blade tip could be used to change the mass flow rate at the stall point and the stall margin. In addition, it had a minor effect on the flow field structure in the tip, so the efficiency at the design point was negligibly changed

(5) A proper amount of the geometric modification (including the forward sweep of the blade tip, expansion of upper meridian and variation in the chord length of the blade tip) can greatly improve the stall margin and keep the aerodynamic performance at the design point nearly unchanged

(6) The results show that for the supersonic compressor rotor, the tip clearance flow, the shock wave structure in the tip region, and their interaction are the key factors influencing the aerodynamic performance of the rotor, and it is also a research area worthy of attention in the future

\section{Notations}

$\begin{array}{ll}\bar{x}: & \text { Modification position } \\ \delta: & \text { Local thickness of the blade profile } \\ \Delta \delta: & \text { Thickness modification } \\ c_{1}, c_{2}, c_{3}: & \text { Weight coefficients } \\ \bar{H}: & \text { Loading coefficient } \\ \mathrm{Ma}: & \text { Mach number } \\ N: & \text { Rotational speed }(\mathrm{rpm}) \\ U: & \text { Tip speed }(\mathrm{m} / \mathrm{s}) \\ \beta: & \text { Inlet flow angle }(\mathrm{deg}) \\ \dot{m}: & \text { Mass flow rate }(\mathrm{kg} / \mathrm{s}) \\ \eta_{k}^{*}: & \text { Efficiency } \\ \pi_{k}^{*}: & \text { Total pressure ratio } \\ \pi_{s}: & \text { Static pressure ratio } \\ \sigma: & \text { Tip clearance. }\end{array}$

\section{Subscript}

$\begin{array}{ll}d: & \text { Design point } \\ s: & \text { Near-stall point } \\ \text { obj: } & \text { Objective value } \\ r: & \text { Blade root } \\ t: & \text { Blade tip } \\ 1: & \text { Inlet. }\end{array}$

\section{Data Availability}

The blade data used to support the findings of this study are included within the supplementary information file.

\section{Conflicts of Interest}

The authors declare no conflict of interest.

\section{Acknowledgments}

This research has been supported by the National Science and Technology Major Project (No. 2017-II-0001-0013). 


\section{Supplementary Materials}

The grid file of the original rotor, which can be generated mesh through the IGG of Numeca software. (Supplementary Materials)

\section{References}

[1] R. B. Dilip and Z. Joseph, "Progress in aero-engine technology (1939-2003)," Journal of aircraft, vol. 41, no. 1, pp. 43-50, 2004.

[2] VAATE, US, "New advanced turbine engine technology development program," International Aviation, vol. 12, pp. 40-42, 2007.

[3] W. K. Stanley, "Pratt engine meets phase 1 IHPTET goals," Aviation Week \& Space Technology, vol. 141, p. 38, 1994.

[4] C. Wuli, L. Qianzhi, and C. Hu, Principle of Aviation Turbomachinery, Northwestern Polytechnical University Press, Xian China, 2009.

[5] A. Kantrowitz and C. Donaldson, Preliminary Investigation of Supersonic Diffusers, 1945, NACA-ACR -L5D20.

[6] A. Kantrowitz, The Supersonic Axial-Flow Compressor, 1946, NACA-Report 974, NACA-ACR- L6D02.

[7] K. Küsters and A. Schreiber, "Compressor cascade flow with strong shock-wave/boundary-layer interaction," AIAA Journal, vol. 36, no. 11, pp. 2072-2078, 1998.

[8] E. Benini, "Three-dimensional multi-objective design optimization of a transonic compressor rotor," Journal of Propulsion and Power, vol. 20, no. 3, pp. 559-565, 2004.

[9] Y. S. Lian and M. S. Liou, "Multi-objective optimization of transonic compressor blade using evolutionary algorithm," Journal of Propulsion and Power, vol. 21, no. 6, pp. 979-987, 2005.

[10] R. Pan, Z. Song, and B. Liu, "Optimization design and analysis of supersonic tandem rotor blades," Energies, vol. 3228, no. 13, p. 3228, 2020.

[11] G. Venturelli and E. Benini, "Kriging-assisted design optimization of S-shape supersonic compressor cascades," Aerospace Science and Technology, vol. 58, pp. 275-297, 2016.

[12] Z. Zhenggui, Q. Ming, X. Xu, and M. Yulu, "Automatic optimization design of compressor/fan 2D blade profile," Acta Aeronautica et Astronautica Sinica, vol. 32, no. 11, pp. 19871997, 2011.

[13] Q. Ming and Z. Zhenggui, “Application of numerical optimization method in aerodynamic design of axial compressor rotor," Journal of Nanjing University of Aeronautics and Astronautics, vol. 45, no. 1, pp. 75-81, 2013.

[14] Z. Ming and S. Shudong, Principle and Application of Genetic Algorithm, National defense industry press, Beijing, 2001.

[15] L. Reid and R. D. Moore, Design and Overall Performance of Four Highly Loaded, High-Speed Inlet Stages for an Advanced, High-Pressure-Ratio Core Compressor, 1978, NASA TP-1337.

[16] Q. Ming, S. Ma, Z. Zhenggui, C. Ti, and H. Yan, "Transonic compressor rotor's supersonic airfoil design," Journal of Engineering Thermophysics, vol. 37, no. 6, pp. 1173-1180, 2016.

[17] C. Hah, S. L. Puterbaugh, and A. R. Wadia, "Control of shock structure and secondary flow field inside transonic compressor rotors through aerodynamic sweep," ASME 1998 International Gas Turbine and Aeroengine Congress and Exhibition, 1998.
[18] J. D. Denton and L. Xu, "The effects of lean and sweep on transonic fan performance," ASME Turbo Expo 2002: Power for Land, Sea, and Air, 2002.

[19] J. D. Denton and L. Xu, "The exploitation of threedimensional flow in turbomachinery design," Journal of Mechanical Engineering Science, vol. 213, no. 2, pp. 125-137, 1988.

[20] G. S. McNulty, J. J. Decker, B. F. Beacher, and S. A. Khalid, "The impact of forward swept rotors on tip clearance flows in subsonic axial compressors," Journal of Turbomachinery, vol. 126, no. 4, pp. 445-454, 2004.

[21] G. Xingmin, F. Zhu, K. Wan, and J. Donghai, "Effects of inlet circumferential fluctuation on the sweep aerodynamic performance of axial fans/compressors," Journal of Thermal Science, vol. 20, no. 5, pp. 383-394, 2013.

[22] C. Hao, F. Zhu, J. Donghai, and G. Xingmin, "Effect of blade sweep on inlet flow in transonic compressor rotors," Journal of Aerospace Power, vol. 31, no. 4, pp. 857-866, 2016.

[23] W. E. Moeckel, Approximate Method for Predicting Form and Location of Detached Shock Waves Ahead of Plane or Axially Symmetric Bodies, 1949, NACA-TN-1921. 